The NASA Constellation University Institutes Project: Thrust Chamber Assembly Virtual Institute

\author{
P. Kevin Tucker, Jeffry A. Rybak, James R. Hulka, Gregg W. Jones, \\ Tomas Nesman and Jeffrey S. West
}

\title{
I Abstract
}

This paper documents key aspects of the Constellation University Institutes Project (CUIP) Thrust Chamber Assembly (TCA) Virtual Institute (VI). Specifically, the paper details the TCA VI organizational and functional aspects relative to providing support for Constellation Systems. The TCA VI vision is put forth and discussed in detail. The vision provides the objective and approach for improving thrust chamber assembly design methodologies by replacing the current empirical tools with verified and validated CFD codes. The vision also sets out ignition, performance, thermal environments and combustion stability as focus areas where application of these improved tools is required. Flow physics and a study of the Space Shuttle Main Engine development program are used to conclude that the injector is the key to robust TCA design.

Requirements are set out in terms of fidelity, robustness and demonstrated accuracy of the design tool. Lack of demonstrated accuracy is noted as the most significant obstacle to realizing the potential of CFD to be widely used as an injector design tool. A hierarchical decomposition process is outlined to facilitate the validation process. A simulation readiness level tool used to gauge progress toward the goal is described.

Finally, there is a description of the current efforts in each focus area. The background of each focus area is discussed. The state of the art in each focus area is noted along with the TCA VI research focus in the area. Brief highlights of work in the area are also included.

\section{Introduction}

\section{A CUIP Objectives}

The NASA Constellation University Institutes Project (CUIP) is a consortium of universities charged with addressing technical challenges in NASA's Exploration Systems Mission Directorate's development programs, particularly fundamental technical challenges of importance and relevance to Constellation Systems.

The overall objectives of the CUIP are to perform research and development that addresses critical Constellation needs; enhance and broaden the ability of the nation's universities to meet the needs of NASA's programs; expand the nation's talent base for NASA mission-related research and development and technology maturation; and strengthen NASA's ties to academia through long-term, directed, and sustained investment. The Project provides technical oversight 
for the university research efforts, performs financial management, manages the review processes, and fosters relevant relationships between the university researchers and NASA Constellation Systems for each of the CUIP's technical tasks. Project management resides at NASA Glenn Research Center, while NASA Ames Research Center, NASA Glenn Research Center, NASA Johnson Space Center, NASA Langley Research Center, and NASA Marshall Space Flight Center all provide technical points of contact. Furthermore, a CUIP advisory board, comprised of United States Air Force and industry representatives, provides both input on CUIP execution and task assessment and conduits for information back to their respective organizations.

The three contractual institutes, along with the aforementioned NASA team and advisory board make up the CUIP. The three institutes, shown in Figure 1, are the Institute for Future Space Transport (led by the University of Florida), the Space Vehicle Technology Institute (led by the University of Maryland), and the Rocket Engine Advancement Program (led by the University of Alabama at Huntsville). In total, the three institutes that make up CUIP are comprised of 17 geographically disparate universities, nearly 60 technical tasks, 100 researchers and 130 students. Last year, the CUIP supported over 200 workshop, conference, and archival publications.

\section{B Strategy for meeting the CUIP objectives}

The CUIP Management Team strategy for meeting the CUIP objectives noted above centered on a three-pronged set of organizational efforts aimed at insuring efficient development of relevant technology.

First, the CUIP was functionally organized by technical area, which allows the CUIP to achieve critical mass in key areas through coordinated, complimentary activities. The entire portfolio of tasks in the ISFT, SVTI and REAP University Institutes that comprise CUIP was aligned according to a Constellation Project-focused work breakdown structure (WBS) by the CUIP Management Team. Each top level entity in this WBS was designated a Virtual Institute (VI). This VI concept helps unify, from a strictly technical standpoint, the entire university arrangement within CUIP, establishing a collaborative environment that crosses not only contractual institute lines but university lines, as well. In short, the VIs promote technical collaboration as the norm rather than hoping that collaboration occurs by happenstance. The CUIP VIs are listed below and are depicted in Figure 2.

\subsection{Thrust Chamber Assembly}

3.0 Propellant Storage and Delivery

4.0 Structures and Materials for Extreme Environments

5.0 Re-entry Aerothermodynamics

6.0 Systems Analysis 
Secondly, each VI in the.WBS was required to establish a clear vision relevant to support for the Constellation Project. This vision is the thread that ties all the tasks within a VI together into a set of products that clearly benefits the Constellation Project mission.

Thirdly, each VI was to generate a Technology Roadmap to facilitate efficient execution of the vision.

\section{Scope of the paper}

This paper documents the organization of the TCA VI and its functions in developing relevant technology to support the Constellation Project. First, the TCA VI vision is presented and discussed in terms of the objective, scope and approach. The vision calls for new TCA design tools. The SSME development program is used to illustrate this need and to make the point that the key to TCA design is the injector. Thus, the focus of these new tools should be the injector. The vision also establishes the five focus areas on which the TCA VI must concentrate in order to impact the Constellation project.

CFD is noted as having the potential to meet the injector design tool need. Obstacles to achieving that potential as well as design tool requirements are noted as well. Lack of demonstrated solution accuracy is pointed out as most significant obstacle in achieving the TCA VI vision. The process of verification and validation is noted as the primary path to quantifying and building the required confidence.

The roadmap process to execute the vision is discussed in some detail. Since the overall TCA and injector problems are very complex, a hierarchical decomposition process is used to facilitate the validation. The Simulation Readiness Level (SRL) concept is put forth as a way to objectively evaluate progress against all the design tool requirements, although accuracy is the focus here. The SRL is also shown to be useful in integrating the CFD code and model improvements into production computing capability that ultimately supports Constellation combustion devices design.

Finally, each of the five focus areas is discussed in terms of design and design tool issues and how the TCA VI is addressing those issues.

\section{CUIP TCA VI Vision}

\section{A Vision Statement}


The TCA VI vision.is: To enable, by development, verification and validation, . Computational Fluid Dynamics (CFD) tools for use in multi-disciplinary simulations of the liquid rocket engine TCA hardware in terms of ignition, performance, thermal environments and combustion stability so as to affect the TCA design process in a positive and timely manner. The vision succinctly states the TCA VI objective, the scope of the objective and the approach to meeting the objective.

The objective is to enable CFD tools for timely use in the TCA design process. The scope of the objective encompasses ignition, performance, thermal environments and combustion stability. These are four key TCA areas where there are critical design requirements. First, the engine must ignite very reliably. This is especially true for upper stage engines. Next, the TCA must typically operate at a very high percentage of its theoretical performance capability. Finally, this performance must occur within constraints for thermal environments and combustion stability. The scope sets out the four of the five Focus Areas for the TCA VI. They are: (1) ignition, (2) performance, (3) thermal environments and (4) combustion stability.

The approach to meeting the stated objective is to develop, verify and validate CFD tools. Code development, verification and validation is the fifth TCA VI Focus area. All five Focus Areas will be discussed in more detail later.

\section{B TCA VI Objective}

As noted above, the TCA VI objective is to enable CFD tools for timely use in the TCA design process. The current focus for these CFD design tools is the Constellation Project and the multiple engine designs or major engine modifications required to meet the Moon-Mars goals. Implicit in the objective portion of the Vision is the assumption that new design tools are needed. This section will attempt to objectively validate that assumption by looking back at the Space Shuttle Main Engine (SSME) development process. The point will also be made that the injector is the heart of TCA design. The potential of CFD for use as a TCA/injector design tool will be examined along with obstacles that thus far have hampered realization of that potential. Finally, general requirements for CFD-based TCA/injector design tools are proposed.

A typical rocket engine TCA, shown notionally in Figure 3, is comprised of an injector, combustion chamber, nozzle and the associated ducts and manifolds required to deliver propellants and coolant. The flows in the TCA are very complex as a result of the both the geometry and the physical processes that occur there. An injector, shown in Figure 4, is made up of many, often hundreds, of individual elements designed to facilitate reliably efficient propellant mixing and burning both during the start transient when ignition occurs and during main stage 
operation when the performance requirement must be met. The oxidizer and fuel can be injected at various thermodynamic states (e.g. ideal gas, liquids or real fluids) depending on the particular propellants, the engine cycle and the chamber pressure. Even for a given propellant combination and engine cycle, the chamber pressure, and thus the propellant state, varies during engine operation from the start transient to main stage to the shut down transient. Depending on the propellant combination, combustion processes in the TCA head end can include propellant atomization, evaporation, mixing, burning and soot formation. These processes are further complicated in that they are typically unsteady and three-dimensional. They also occur in a high pressure, high temperature environment. Accordingly, heat transfer to all solid surfaces, such as the injector element itself, injector face and chamber/nozzle wall (which may include film cooling), becomes a very important issue regarding hardware life requirements. Finally, these processes must occur in a controlled manner so as not to couple with certain other TCA processes in such a way that would cause combustion instability. As the combustion processes are completed in the TCA head end, the hot, high pressure products flow though the combustion chamber and are accelerated from the low subsonic regime through the nozzle and exhausted at supersonic speeds up to approximately Mach 6.

Many of the legacy injector design tools have been in use for over forty years. They are typically zero- or one-dimensional and empirical and thus limited in both depth and breadth. Since they do not account for many of the design details and complex physical processes that govern injector operation, their use is mostly limited to small perturbations of rather simple existing designs. Further limitation stems from the tool's focus on performance and stability with only secondary emphasis on ignition and environments. Figure 5 shows severe chamber wall blanching and cracking. These manifestations of the three-dimensional, injector-induced environments are proof that the processes that caused them are also three-dimensional.

It is not therefore surprising the TCA/injector design methodology based on these legacy tools yields a design that lacks robustness. The SSME development program provides a good historical reference to examine the implications of the use of these legacy design tools, most of which are still in use today. The SSME, shown during a test firing in Figure 6, was the first fully reusable cryogenic rocket engine developed. It was also the first staged combustion cycle engine developed in the United States. The SSME full scale development program was initiated in April, 1972 and culminated nine years later in April, 1981.

A chronological plot of the 18 major SSME combustion devices failures through 1988 is shown in Figure 7. Half of the failures occurred in the two year period that bracketed the first Space Shuttle launch in 1981. These failures occurred well into thee development program; after 
over 100,000 seconds of accumulated engine test time. Figure 8 shows hardware damage typical of these failures. This particular incident was a main injector failure 233 seconds into a test on July $15 ; 1981$; just three months after the first launch. The consequence of using these zero and onedimensional design tools is a costly and time consuming test, fail, fix development program.

Although each TCA component has its own challenges which must be addressed to meet design requirements, the injector is the key to a good, robust TCA design. It is well known that the details of injector design govern, to a large extent, ignition, performance, environments in the entire combustor, and stability. The particular manner in which the complex set of physical processes occurs as the result of injector design and operation is fundamental to meeting each of the critical TCA design requirements. For example, the igniter can work perfectly, but injector must be designed to provide an ignitable propellant mixture at the proper time and location for successful ignition. Nozzle efficiency may approach $100 \%$, but if the injector does not provide efficient propellant mixing and combustion, the overall TCA performance will be low. The combustion chamber can be sufficiently cooled from an overall sense, but poor injector design can cause local areas of serious chamber wall damage. Injector design that results in coupling of some of the key flow/combustion processes can cause instabilities that must be mitigated by often complex damping devices.

Additionally, injector design is made more complex by the often competing trends among the requirements. For example, higher injector performance typically results in more severe environments. Often, stable injector operation is achieved with some performance penalty.

Figure 9 provides a detailed mapping of the SSME major combustion devices failures. Over $75 \%$ of those failures occurred in either the main injector or one of the preburner injectors. The design space that contains an injector with reliable ignition characteristics, high performance and stable operation with sufficiently benign environments has historically been located only after several time consuming and costly design, test, fail cycles. This is a direct consequence of modeling very complex flow phenomena with relatively simple, empirical tools.

CFD is a tool that offers the potential to model the complex physical processes and geometries of the injector and entire TCA to evaluate ignition, performance, thermal environments and combustion stability in terms of the details of injector design and operation. The injector design tools are in a transitional period between the exclusive use of one-dimensional, empirically based tools and more extensive reliance on CFD. Currently, legacy tools are overwhelmingly used for injector design, in large measure because the promise of CFD as an injector design tool is unrealized to date. At this point, $\mathrm{CFD}$ is not typically included in the original design plan, budget 
or schedule. In the isolated cases where CFD is included in the design plan, it is mostly for qualitative trend analysis focused on a specific, narrow issue. Occasionally, there is an attempt to use CFD in the "we have no other option" mode. Predictably, results obtained in this mode are not of the quality to encourage more CFD use.

There are three major obstacles to increasing the reliance on CFD as an injector design tool. The first obstacle is an inability to sufficiently model the details of the physics and geometry associated with the injector. Most injector solutions are the product of the ideal gas assumption and very simple chemistry and turbulence models. Production CFD capability is limited to steady flow solutions of single elements typically generated assuming axisymmetric geometries. Very few three-dimensional, multi-element solutions can be generated during the relatively short design cycle. The second obstacle is the slow solution turnaround time. Reliable robust design is the product of examination of large parametric spaces considering both single and multi-element injector issues. Many injector solutions must be generated early in the design phase. Typically, only a few single element solutions are completed in this time frame. The third obstacle is the lack of demonstrated accuracy of the solutions that are generated. There is no agreed upon verification and validation process. Very little methodical, quantitative validation work has been done to date. Also, relevant data at conditions appropriate for validation is scarce.

Proponents of extensive use of CFD for injector design are obliged to set requirements that address the obstacles noted above. The requirements for new CFD-based injector design tools must also be derived in the context of the hardware design issues and address known shortcomings of the legacy design tools. The first requirement is solution fidelity. CFD-based design tools must be able to calculate performance and multi-dimensional thermal environments and evaluate ignition and combustion stability as a function of injector design details and associated flow physics. The second requirement is solution robustness. CFD-based design tools must be able to produce large numbers of solutions over a parametric space during the design phase to ensure a robust design. The final requirement is demonstrated solution accuracy. Solution accuracy must be demonstrated to yield quantitative results in terms of ignition, performance, thermal environments and combustion stability.

Obviously, these requirements are related. For instance, increasing solution fidelity, either in terms of physics or geometry, typically results in slower solution turn around time, thus decreasing solution robustness. Theoretically, the accuracy level of the solution should be increased. A key point needs to be made here. Since the goal is use of CFD for injector design, this theoretical accuracy increase must be quantified through demonstration. This accuracy 
demonstration requires significant, methodical work and represents a non-trivial expenditure of resources. There will be more discussion of this point in the following section.

\section{TCA VI Approach}

The approach used by the TCA VI to achieve the objective just described is to develop, verify and validate state of the art CFD codes and models. Marshall Space Flight Center is funding development of two CFD algorithms in the Loci computing platform. The Loci effort is partially funded under CUIP while the algorithm work on Loci-CHEM and Loci-STREAM is funded outside CUIP. The Loci-CHEM and Loci-STREAM codes have been chosen as the potential TCA/injector design tools. The modularity embodied in the Loci platform enables all new models and improvements developed in the CUIP TCA VI to be efficiently transplanted into Loci where they are available for use by users of either Loci-CHEM or Loci-STREAM.

How should confidence in simulations and modeling for design be critically assessed, and, where necessary, improved? If CFD is to be used as an injector design tool, code developers and code users must deal with a critical issue. Oberkampf et al ${ }^{3}$ note that verification and validation of computational simulations are the primary methods for building and quantifying this confidence. They provide an insightful discussion of the issue in a report that presents their view of the state of the art in verification and validation. The TCA VI has adopted this philosophical framework to guide what is an extensive verification and validation effort. Achieving and demonstrating the accuracy level required for CFD to be considered the primary injector design tool is the most significant obstacle in reaching the TCA VI objective. Hence, the verification and validation effort is a large and critical part of the TCA VI effort.

Two model definitions help to facilitate the verification and validation overview extracted from Oberkampf et al. The conceptual model is composed of the partial differential equations (PDEs) for conservation of mass, momentum and energy along with auxiliary equations such as turbulence models and all of the initial conditions and boundary conditions of the PDEs. The computerized model is the computer code which implements the conceptual model. Oberkampf et al also employ formal definitions of verification and validation to help make their arguments. Verification is defined as the process of determining that a model implementation accurately represents the developer's conceptual description of the model and solution to the model. Validation is defined as the process of determining the degree to which a model is an accurate representation of the real world from the perspective of the intended use of the model.

Verification deals with the fidelity between the conceptual model and the computerized model. Validation deals with the fidelity between the computerized model and experimental 
measurements. Verification is the first step in the overall validation process. It effectively.provides evidence that the conceptual model is solved correctly by the discrete-mathematics computer code. Validation provides evidence for how accurately the computerized model simulates reality. According to Roache, ${ }^{4}$ verification deals with mathematics and validation deals with physics.

Verification is the process which identifies, quantifies, and reduces errors in the computational model and its numerical solution by comparing the code with various types of highly accurate solutions. Verification results in quantification of numerical accuracy by demonstration.

Validation is a more complex issue and is actually an ongoing process. According to Oberkampf et al, the goals of validation are to identify and quantify the error and uncertainty in the conceptual models, estimate the error in the computational solution, estimate the experimental uncertainty and compare the computational results with the experimental data. Because true validation experiments are usually not feasible on complex systems such as a full-scale rocket engine thrust chamber assembly, a building block approach is recommended by Oberkampf et al. This approach divides complex systems into at least three progressively less complex tiers: subsystem cases, benchmark cases and unit physics problems.

\section{Executing the Vision-the TCA VI Roadmap}

\section{A Hierarchical Decomposition}

For very complex systems like the rocket engine TCA, Oberkampf et al recommend a hierarchical decomposition of the complete system to facilitate validation. This approach, depicted in Figure 10, starts with the complete system and decomposes it into progressively simpler problems.

The complete system, the TCA in this case, consists of the actual engineering hardware for which a reliable computational tool is needed. Data are measured on the engineering hardware under realistic operating conditions. In the context of validation, the quantity and quality of measurements are very limited.

The subsystem cases represent the first decomposition of the actual hardware into simplified systems or components. The TCA decomposes into the injector, combustion chamber, nozzle and associated ducts and manifolds. Measured data at this decomposition level is typically limited to engineering parameters of clear design interest. Budget and schedule preclude obtaining a complete set of modeling parameters.

Benchmark (or model problem) cases constitute the second decomposition level. Here, special hardware is fabricated to represent the main features of each subsystem. This hardware is geometrically simpler than the corresponding subsystem hardware. At this level, more of the 
required modeling data can be measured and is usually presented with estimates of data . uncertainty. In the case of the injector subsystem, this decomposition level is comprised of subscale hardware such as $40 \mathrm{klb}_{\mathrm{f}}$, small multi-element and single element injectors.

The final decomposition level is the unit problem level. This level represents the total decomposition of the complete system. One element of physics occurs in each unit problem. Highly accurate data is obtained accompanied by extensive uncertainty analysis. Examples of some unit problems for the injector benchmark cases are shown in Figure 11.

The TCA VI validation effort is currently focused mostly on the benchmark level. Unfortunately, little validation on the unit physics problems has been accomplished in the CUIP to provide the foundation for this work. Figure 12 helps to illustrate the desired relationship between the unit problems and the benchmark (or model) problems. The plot shows the comparison of chamber wall heat flux from a CFD solution compared to experimental data for a benchmark level single element injector and chamber. The comparison is very reasonable in the head end portion of the chamber, but less so in the downstream portion. Assuming good quality CFD solutions have been produced in terms of convergence, mass conservation, grid independence, etc., experimental data sets at this level typically contain no other data to guide the validation effort in the sense of understanding what the issues are and how solution accuracy may be improved. Actually, this more fundamental data such as velocity, turbulence and species profiles is available at the unit problem level. The validation effort should start at this level. Historically, misconceptions about the importance of the validation process have retarded validation efforts associated in general and especially at this fundamental level. Since validation work at the unit physics level is viewed by resource providers as too basic and not connected closely enough to the "real problem", resources are typically not provided for this type of effort. This level of validation work, both in acquiring data and performing the actual code validation is ideal for universities and must be pursued with vigor in the TCA VI if the objective is to be met.

\section{B Evaluation of progress}

There must be some way of gauging progress toward the objective to enable CFD as a TCA/injector design tool. The most straightforward approach is to evaluate progress against the fidelity, robustness and accuracy requirements set out earlier. The Simulation Readiness Level (SRL) assigns a numerical value to each of these requirement components according to its level as shown in Table 1. Fidelity has to do with the degree of solution faithfulness to the problem geometry, boundary conditions and physics. Robustness is a function of the quality and quantity of solutions that have been produced in the context of time. Accuracy is reflective of the demonstrated level of solution agreement to the actual problem and ultimately a parametric space 
of relevant design variables associated with that problem. In terms of accuracy, code verification results in an accuracy level of 0 relative to a particular model problem. No statement of solution accuracy should be made without appropriate code verification. Accuracy levels 1 and 2 are associated with the unit problems. Clearly, as noted above, significant work should be done at this level before proceeding to the benchmark problems at level 3. Levels 4 and 5 are associated with the system/subsystem of interest.

\section{Technology definition and integration}

Use of the SRL concept just described also facilitates the technology definition and ultimately integration required for improved design tool capability. Existing CFD tools at MSFC are used to support the needs of current programs. The SRL is used to evaluate the level of current capability of these simulations. This SRL is compared with a desired SRL for design support. The deficit defines an SRL gap in terms one or more of the SRL components; fidelity, robustness or accuracy. This gap feeds the CUIP TCA VI technology roadmap process in terms of tasks that need to be undertaken.

As models and code improvements are made, progress is evaluated using the SRL process. When they are objectively shown to be an improvement over the existing capability, they are integrated into the production version of one or both of the Loci algorithms for program support use.

\section{Discussion of the TCA focus areas}

As noted above, the TCA VI vision leads to five Focus Areas. The first four of these, ignition, performance, environments and combustion stability are all TCA areas where there are design requirements and/or constraints. The fifth area, code and model development, verification and validation is a more general area of work that underpins the efforts in the other four areas.

Some general comments are appropriate before the discussion of the individual tasks. Philosophically, there has been a consistent effort made to pair modeling tasks with experimental tasks the function of which is to gather validation data. Experience has shown that this synergy leads to a set of data better suited for code/model validation. Since the majority of the work done in the TCA VI is pushing technology, many of the experimental tasks, and the accompanying modeling, serve two purposes. First and foremost, the experimental tasks are to acquire the type and quality of data required to validate CFD cods for TCA/injector design. Secondly, many times these efforts supply additional understanding of the underlying physics of the issue being examined. 
Each of the five TCA VI Focus Areas will be discussed below. The discussion for each Focus Area will begin with background and justification for additional research into the area. Next, the state of the art, with focus on the analysis for design, will be addressed. The issues of CUIP concentration in each Focus Area will be noted followed by a brief highlight of the tasks in each Focus Area. It should be noted that the details of each of these tasks can be found in the series of accompanying papers referenced at the appropriate places below.

\section{A Ignition}

\section{Background and justification}

Ignition of liquid propellant rocket engines is a significant requirement due to the fact that failure to ignite results in loss of vehicle. While earth-to-orbit boost engines have less risk from non-ignition since health monitoring and on-pad abort controls can allow these engines to shut down safely and recycle for a later launch attempt, no such benefits apply to upper-stage and inspace engines. For these engines, especially those that use non-hypergolic propellants and whose missions require multiple starts, ignition may be the most important factor in the overall engine reliability. This risk led the Apollo program to select hypergolic propellants engines for the lunar descent, ascent and earth-return missions, and to expend enormous resources to verify ignition reliability of the $\mathrm{O}_{2} / \mathrm{H}_{2} \mathrm{~J}-2$ engine for the Saturn upper-stage and trans-lunar burns.

For upper-stage and in-space engines that must relight, conditions prior to the initial ignition can be controlled to some extent, which reduces the risk of the initial ignition. However, successive ignitions become more problematic since residual combustion products from previous engine operation can condense in valves, piping, or on injectors or other surfaces, thereby creating difficulties for subsequent starting procedures. Even the highly reliable ignition characteristics of hypergolic propellants vanish if the valves required for their injection fail to operate.

\section{State of the art in ignition transient analysis}

Currently, ignition transient analysis capability during engine design, development, and operation is largely one-dimensional and empirical. While these lumped-parameter analyses have been used for decades, the capability to analyze local transient events, such as the actual ignition of propellants in the combustion chamber, is surprisingly immature. In this area, the use of advanced analysis techniques such as combustion computational fluid dynamics (CFD) is practically nonexistent. Unfortunately, failures occur locally, not globally, so use of current one-dimensional and empirical 
models means that developing new designs (or better understanding of current designs) requires extensive full scale testing. Consequently, development of ignition systems has been almost exclusively empirically based, occurring on the full-scale engine and requiring significant numbers of full-scale engine tests to develop even basic understanding of the issues. Non-ignitions, when they occur, usually result in a failure investigation involving a detailed examination of all aspects of engine hardware and operating procedures involving ignition, as well as more full scale engine tests.

\section{CUIP research focus}

Ignition research and development in CUIP addresses this deficiency in analysis capability. The primary objectives are to improve the capability and fidelity of time-accurate flow analysis by validating a CFD-based analysis methodology with appropriate experiments. The experiments will evolve from bench-scale size with two-dimensional or axisymmetric geometries and non-reacting flows to three-dimensional and multi-element geometries with reacting flows. Ultimately, the analysis will also include three-dimensional and multi-element effects, and the effects of real fluid properties. Thus, more detailed information about reliability-critical factors can be made available earlier in engine development.

To define the task plans for CUIP-funded research and development on ignition, the overall problem must be defined and then divided into portions that can be progressively developed and validated. The ignition transient in a liquid propellant rocket combustor can be divided into multiple steps, which include (1) filling a local region in the combustion chamber with unreacted propellants, (2) local mixing of the unreacted propellants, (3) applying energy to the local region sufficient to ignite the local mixture, (4) ignition and stabilization of a small kernel of hot gas in the local region, and (5) propagation and stabilization of the flame across the combustion chamber. All of these steps are important to understand the ultimate ignition reliability. However, the flow conditions in the injector and chamber during ignition are complex, and attacking the whole problem at once including two-phase and three-dimensional flow, transient mixing, and nonequilibrium and detailed chemistry - is largely intractable at this time. How to select portions of this overall problem is defined below.

The two requirements for ignition system development that are probably most critical are (1) providing the correct mixture ratio and propellant conditions at the correct time in the start sequence and location in the combustion chamber, and (2) providing a reliable energy source. To understand the first requirement, only the first two steps in the ignition transient outlined above must be adequately characterized; i.e., predicting the spatial and temporal distributions of propellants in the injector and combustion chamber prior to the initiation of reaction of the propellants. Initiating the 
reaction would not be necessary; so that attacking the problems of non-equilibrium chemistry can be postponed.

There is little analytical methodology or empirical data currently available to assist in predicting the evolution of local mixture ratio prior to the initiation of chemical reaction. Typical information available includes flammability limits from well-mixed mixture ratios in large volumes. Predicting local mixture ratios just prior to ignition thus is recognized as a critical need to improve ignition system designs and increase ignition system reliability. One line of CUIP research thus is defined along this direction.

CFD modeling tools were chosen for this application since they were the most credible means to improving the fidelity of such a three-dimensional, time-accurate flow analysis. To validate these models, transient mixing experiments are required, which must be closely tied to the model development to provide the most benefit to both experiment and model.

Geometric and propellant simplifications can make the time-dependent calculations readily tractable with current computational capabilities, and provide simpler experimental requirements, but still leave enough of the overall physics intact to make substantial improvements in modeling capability. Consequently, initial research with gaseous propellants is acceptable to provide the simplest experimental and analytical conditions. Subsequently, the test fluids must include two-phase conditions to adequately demonstrate capability to model real engine effects. Eventually, the research will evolve into reacting flow conditions, where the second important requirement - the energy required to ignite the flow - will be studied.

\section{CUIP research highlights}

Similar to other CUIP focus areas, the research and development in ignition is divided into experimental programs and analytical tool development programs. The experimental programs will gather space- and time-dependent mixture fraction data on typical injector/chamber geometries, which can be used to validate analytical models as well as develop more reliable geometries for ignition. The analytical prediction tool will be developed to model the pre-ignition transient from the initial opening of the fuel valve to the time the spark plug, laser, torch, or other ignition source is activated.

Experiments with gaseous propellants at ambient backpressure are ongoing at the Purdue University (Ref 1). The current experiments funded by CUIP have continued from a year-long MSFC-funded program in 2005 (Refs 2-4). The test article is a two-dimensional "slab" injector and rectangular chamber with optical access, and is shown in Fig. 13. Test fluids include gaseous nitrogen 
for the oxidizer simulant and helium for the fuel (hydrogen) simulant. The nitrogen was seeded with nitric oxide (NO) as a fluorescent tracer species to allow for Planar Laser-Induced Fluorescence (PLIF) diagnostics to quantitatively measure the instantaneous mixture fraction in the chamber. Because the nitric oxide tracer in the nitrogen will fluoresce while the belium will not fluoresce, the intensity of the fluorescence is a measure of how much helium is mixed with the nitrogen, or essentially a measure of the local mixture ratio.

The injector and chamber were designed so that the experimental data could be compared directly with the results of transient CFD simulations. The modeling effort for these gas/gas experiments is also ongoing (Refs). The General Equation and Mesh Solver (GEMS) CFD code at Purdue University was selected for the initial validation. The objectives of the code development include 1) guiding the designs and test plans for the experiment, 2) provide an assessment of existing capability for modeling unsteady mixing phenomena in the context of rocket engine ignition, and 3) serve as a point of departure for improving the accuracy and turn-around time so CFD can be used as a tool for designing ignition systems for rockets. To do this, the tool must be able to accurately predict at what time in the start transient ignitable mixtures exist as well as the spatial location of such mixtures. To date, numerical simulations of the unsteady mixing between two dissimilar gas streams emerging from separate, fully developed turbulent channel flows into a common mixing chamber have been presented. The key area of interest was the transient mixing between an established, steady flow of $\mathrm{N}_{2}$ into which a He stream was injected. Comparisons between the computations and experimental flow visualizations indicated that the computations provided a fair prediction of the flow, but the experiment indicated mixing rates that were considerably faster than those predicted in the computations. A typical comparison between transient experiment and computation is shown in Fig. 14.

For cryogenic upper-stage and in-space engines, the flow conditions in the injector and chamber are two-phase oxygen mixed with gaseous fuel (hydrogen or methane) at near-vacuum conditions, with multi-element, three-dimensional geometries. This problem presents two additional complexities to the gas/gas experiments - two-phase flow and three dimensional injector geometries. A program at the University of Maryland provides some initial research into these new characteristics (Ref 5). This program is examining the mixing in a coaxial element rather than a slab element, and is developing the capabilities to measure two-phase flows by using liquid nitrogen instead of gaseous nitrogen for the oxygen stimulant. Initial testing to capture the two-phase flow characteristics has used Particle Image Velocimetry (PIV) (Ref 6), infrared, and high-speed Schlieren techniques (Ref 7), an example of which is shown in Fig. 15. 


\section{B Performance}

\section{Background and justification}

The purpose of the rocket TCA is to convert the propellant potential energy into thermal energy in the combustion chamber via the injector. The task is completed as the nozzle converts the thermal energy into kinetic energy as the flow is accelerated and exhausted creating thrust to power the vehicle. TCA performance is a measure of efficiency in that it is thrust developed per rate of propellant consumption. Since performance contributes significantly to the vehicle velocity at propellant burnout, it has a large effect on vehicle range and payload.

Performance in the injector/chamber portion of the TCA depends on complex flow phenomena initiated in the injector such as propellant injection, atomization of liquid propellants, vaporization of the atomized liquid, followed by mixing and reaction of the now gasified propellants. The manner and extent to which these processes occur are dependent on many factors including element type, details of the element design, injector pattern and element density on the injector, propellant distribution over the entire injector, whether film cooling is required, etc.

\section{State of the art in rocket performance analysis}

Historically, TCA performance has been arrived at by a multi-step process. First, ideal performance was calculated using a one-dimensional chemical equilibrium technique. Then correction factors were calculated and used as decrements from the ideal value. In the 1970s, the Joint Army, Navy, NASA and Air Force committee developed analytical procedures to calculate the performance corrections in what was a rigorous manner for the time (ref $\mathrm{H} \& \mathrm{H}$, p12). Performance correction factors, anchored on test data, were defined to account for identified losses in the injector/chamber and nozzle.

Subtraction of the nozzle losses from the ideal TCA efficiency leaves what is known as an ideal injector. The actual injector performance is obtained by accounting for inefficiencies that occur as a result of injector design. A vaporization efficiency factor accounted for any propellant fraction that was not available for combustion in the chamber due to the fact that it had not been vaporized. Another efficiency factor accounted for mixing losses due to element design or propellant maldistribution across the injector. Finally, another factor accounted for any fuel that was required to be used to cool the chamber wall.

Recent years have seen the logistics of using this methodology improved by linking the many steps together into a cohesive design tool. This has been done proprietarily by several 
different companies in the rocket propulsion field. The most widely available version is the Rocket Combustor Interactive Design (ROCCID) code (ref Sierra). ROCCID developers advertise a standardized methodology for the analysis of liquid rocket engine combustor steady state performance and combustion stability.

As noted earlier, CFD offers the potential to address the issues historically accounted for by one-dimensional, empirical decrements for physical process inefficiencies in a more rigorous manner. Losses resulting from incomplete vaporization, mixing and propellant maldistribution can theoretically be calculated directly by CFD as a function of propellant feed manifold and injector design details.

Current CFD capability at the practical, production level is limited to homogenous treatment of the propellants. In this case, neither propellant atomization nor vaporization is modeled. The fact that propellants are often injected into the chamber at supercritical conditions (at least for pressure) lends credibility to this necessary assumption. However, some engines operate at pressures below propellant critical pressures. Also, the presence or absence of liquid drops in mixtures at pressures above the pure propellant critical conditions is a matter of current debate.

\section{CUIP research focus}

The performance focus area seeks to provide validation data to quantify the current CFD capability to predict the mixing of propellant streams as a function of the details of the delivery hardware across a relevant parametric space of design details and operational variables. This capability is a critical component to the ability to accurately assess injector performance. Given the homogenous treatment, the focus of validation is on mixing of propellant streams.

\section{CUIP research highlights}

There are currently three tasks in the TCA VI that directly address performance by providing data for validation of propellant mixing. The first task, conducted at the University of Michigan uses gaseous propellants to provide an extensive database for code validation for both reacting and non-reacting coaxial jets at pressures up to 10 atmospheres. Data will be taken on the same rig using the same instrumentation across a wide range of conditions from simple to combusting jets. The non-reacting jet data will be useful at the accuracy level 1/unit problem level. Data will be acquired to measure flame dimensions and standoff distance, mixture ratio profiles, temperatures and chamber pressure. A parallel CFD task is being initiated at the University of Michigan. A picture of the test rig before assembly is shown in Figure 16. 
The other two mixing experiments are being conducted. The first experiment at the University of Florida deals with high pressure GO2/GH2 combustion and is, in a sense, an extension of the University of Michigan tasks just discussed. This experiment will collect spatially resolved species data and chamber wall heat fluxes at chamber pressure of up to 60 atmospheres. A picture of the optically accessible test rig is shown in Figure 17. There is also a parallel numerical underway at the Georgia Institute of Technology using large eddy simulation (LES) to model the experiment. The expectation of the higher fidelity LES effort is a better understanding of what is actually required to model these unsteady reacting flows.

The second experimental effort is concerned with turbulent jet break-up and propellant mixing. Experiments are being conducted at both the University of Florida and the Georgia Institute of Technology. The University of Florida effort uses an Exciplex method to quantify the distribution of liquid and vapor phases. Representative jet liquid and vapor phase distributions from the Florida experiment are shown in Figure 18. The Georgia Tech effort is extending a ketone fluorescence/phosphorescence technique to higher pressures to make similar measurements. A parallel LES effort is being conducted at Georgia Tech to guide the experimental development and validate the LES mixing capability for sub-, trans-, and supercritical regimes.

\section{Thermal Environments}

\section{Background and justification}

The high temperature combustion gases under high pressure in the combustion chamber cause heat transfer issues drive chamber durability in almost all rocket engine TCAs. This fact makes knowledge and management of the magnitude and distribution of thermal loads a key element in successful thrust chamber design. The high combustion chamber heat loads are typically transferred to fuel coolant behind the chamber wall or to film coolant on the hot gas side of the chamber wall, or in some cases to both. Thermal environment definition and management will be even more critical to some of the engines being considered for parts of the Exploration mission. Many of the in-space engine concepts are based on expander cycles where both the chamber heat transfer and coolant pressure drops are key performance drivers. Accurate prediction of the chamber heat loads and reducing the coolant pressure drop requirements are critical to successful expander cycle design.

\section{State of the art in rocket heat transfer analysis}

The vast majority of combustion side heat transfer analysis used in TCA design is onedimensional and empirical. Much of the supporting data has been obtained using sub-scale calorimeter chambers and is also one-dimensional. As shown by the streaks on the chamber wall 
in the Figure 5, the actual heat transfer environment is highly three-dimensional. These local, threedimensional effects are the result of injector design and operation and are dominant factors in determining combustion chamber durability. Determining these peak local environments is generally not possible with the currently used one-dimensional injector design tools. Hence, they are seldom included in the design process, but are usually factored in by including empirical margins of safety on the thermal and structural analyses.

\section{CUIP research focus}

The thermal environments focus area seeks to improve the ability to model the complex physics so that the three-dimensional chamber thermal environments can be accurately simulated during the TCA design phase. In the thermal environments area, the CUIP tasks can be divided into three groups. First, there are two tasks that focus on providing hot side validation data while simultaneously helping to define and understand the combustion heat transfer environment. Second, there are two tasks that focus on providing code validation data and better understanding of active cooling for the combustion chamber. The third group has a single task, which investigates a novel approach to enhanced cooling.

\section{CUIP research highlights}

The Pennsylvania State University and Purdue University are both pursuing tasks to improve understanding of the heat transfer environment by measuring chamber wall heat flux. Penn State task focuses on taking detailed, spatially resolved combustion chamber heat transfer measurements with three single element $\mathrm{LO} 2 / \mathrm{CH} 4$ injectors. The single element chamber is shown in Figure 19. This task is an extension of work done previously using GO2/GH2 and LO2/GH2. Purdue will be acquiring similar data using a 7-element LO2/GH2 injector. Data from both tasks will be used to validate CFD code heat transfer capability, especially in the head in region where the spatial resolution is a function of the injector design details.

Importantly, the data from both tasks will be used to infer the CFD code's ability to accurately simulate the propellant mixing. The heat release rate, and thus the wall heat flux profile, is dependent on propellant mixing. Both of these experiments are at the benchmark level in the hierarchical decomposition. There has been little effort at the unit problem level to support this work. The result is that any discrepancy between the CFD results and the data is difficult to resolve since there is no detailed flow field data to provide additional understanding. The point is that work done out of the proper sequence results in unnecessary inefficiencies in executing the TCA VI vision. 
The two tasks investigating active chamber cooling are being performed at Purdue University and the University of Maryland. Purdue has created an experiment to measure heat transfer and fluid distribution in a high aspect ratio cooling channel at rocket conditions. High aspect ratio coolant channels offer the possibility of enhanced chamber wall cooling over conventional channels. A schematic of the test rig is shown in Figure 20. This task also features a parallel code validation effort, again using the GEMS code.

Researchers at the University of Maryland are investigating near-wall heat transfer and mixing processes that apply primarily to thrust chamber film cooling. Although near-wall mixing is critical in determining heat transfer performance in film cooling configurations, the details of this process are poorly understood. As a result, detailed transport models in film cooling configurations are largely unavailable and empirical correlations are often used. Careful experiments and detailed measurements are required for understanding near-wall mixing dynamics to refine correlations and improve and validate detailed CFD models used in film cooling applications. A schematic of the experiment is shown in Figure 21. There is also a parallel computational effort in this task.

At the University of Florida, foam filled heat exchangers are being studied as a means to increase the fin effects, and therefore the cooling effectiveness, over what has already been demonstrated by the high aspect ratio cooling channels. Figure 22 shows sample CFD solution of a cell in the foam filled heat exchanger.

\section{Combustion Stability}

\section{Background and Justification}

Liquid rocket engine combustion takes place in gas generators, preburners, and/ or main chambers. The unfavorable location or timing of heat release combined with other dynamic processes is the essential ingredient for unstable combustion. The heat release process coupled with chamber acoustics is historically the most destructive form of instability, but other forms of combustion instability result from flow unsteadiness controlling the heat release process. Flow unsteadiness may originate in the streams injected into the chamber, upstream in the injector element itself, or in the propellant manifold.

A major reason for the lack of a fundamental understanding of combustion instability is the complexity and multi-variable nature of the phenomena itself. Initiation and sustenance of combustion instability has been shown to be sensitive to a number of potential driving mechanisms including propellant injection, inter-element injector flow interactions, atomization, secondary atomization of drops, drop heating and vaporization, mixing processes involving the drops and gases, mixture ratio distribution in space and time, chemical reaction and gas dynamics. 
To stabilize engines that had occurrences of combustion instability, passive devices such as baffles and acoustic cavities were incorporated often into the injector face and the combustion chamber. Sometimes injector modifications that ultimately compromised engine performance in terms of cstar efficiency were required to provide stable operation. All of these solutions reduced thrust-toweight performance and, thus, robust design methodologies that could avert combustion instability became the ultimate desired solution.

\section{Current design state of the art/practice}

No fundamentally based design methodology exists for predicting the initiation and sustenance of combustion instability in liquid rocket engines. Models used to predict combustion stability can be broadly categorized as either analytical or numerical. The analytical models include response factor models and time lag models. The response factor approach typically involves the calculation of the open-loop response, i.e., the rate of gas generation, of a given process to an oscillating pressure field of given frequency, amplitude and wave-form. The intuitive nature of this approach is offset by the fact that there is no feedback from the response to the oscillating pressure field. The sensitive time-lag theory is based on approximating the complicated combustion process by a two-step process: the time associated with a static initial process is the insensitive time-lag, and the time associated with the dynamic combustion process is the sensitive time-lag. Empirical modeling parameters must be correlated using combustor test data. In an attempt at industry standardization, both of these models have been incorporated into the ROCCID code. They have been of limited practical use in determining the operative mechanism of stability in liquid rocket engines.

Early numerical models were developed in the 1960s with relatively simple physics in simple geometries. They were used o identify a burning rate parameter and the velocity difference between the propellant drops and the surrounding gas as parameters that indicated tendencies toward instability. Recent years have seen efforts to develop CFD-based tools for instability prediction. To date, the most practical use of CFD in the area of combustion stability has been to use portions of the solutions as higher fidelity inputs to the analytical models noted above.

3. CUIP research focus

The combustion instability research area is comprised of tasks that focus on the essential elements that contribute to the phenomenon. The tasks have been distributed to combine experiments and modeling using the strengths and expertise of the member institutions. Note that the goal is a comprehensive modeling approach that focuses on unsteady heat release rate processes that drive instabilities at differing scales. 
The approach to combustion instability research in the TCA VI is to use computational methods to guide test definition, perform controlled experiments with determinate boundary conditions, and compare test data to computational model results. The result should be a complete set of data from each experiment for computational validation. Early focus is on simple experiments, in terms of geometry and propellants, allowing for evolution of computational methods. The seven tasks in this focus area investigate issues in the broad categories of injection dynamics, heat release processes and acoustics.

\section{CUIP research highlights}

An experimental task at Purdue University tunes the axial acoustics of a single element injector chamber to the injector acoustics thereby creating a set of axial (longitudinal) instability data for response function- and CFD-based predictive tools. A model of the test rig is shown in Figure 23. Another experiment At Penn State University seeks to demonstrate transverse acoustics driven by a variable set of injectors. They have developed a testbed for studying uni-element and multi-element injector flowfields under realistic conditions in which they are applying state-ofthe-art in instrumentation and diagnostic techniques to understand and identify the driving physical/chemical mechanisms that lead to high frequency instability. This experiment has demonstrated excitation of transverse modes, and is progressing through parameter variations towards a larger amplitude response. A schematic of the multi-element chamber is shown in Figure 24. 
Both of these experimental tasks are supported by a parallel CFD modeling effort at Purdue University. The objectives of the modeling task are to support the design and development of the two test rigs and then, using the data collected in the test, provide an assessment of CFDbased tools for predicting the occurrence of combustion instability in practical rocket combustors. A sample calculation modeling the multi-element rig under development at Penn State University is shown in Figure 25.

Another effort at the University of Alabama in Huntsville has successfully simulated the acoustic response of a chamber with sinusoidal oscillations from small perturbations and high amplitude steep fronted waves from larger perturbations. Acoustic cavities that passively attenuate these oscillations have been investigated computationally and an experiment to create a data set for validation is in progress.

And finally, a more fundamental experiment at the University of Maryland is investigating the flame / acoustic interaction in terms of injection flow density gradient. A representative set of $\mathrm{OH}^{*}$ chemiluminescense images of $\mathrm{GO}_{2} / \mathrm{GH}_{2}$ shear coaxial injector subjected to asymmetric acoustic forcing is shown in Figure 26. The experiment and parallel modeling suggest that the density gradient plays a significant role in amplifying interactions.

\section{E CFD Code/Model Development, Verification and Validation}

1) Essential Elements of the area as it relates to rockets.

In relation to rockets, Code and Model development is the primary activity through which additional benefit of analysis is achieved. Additional benefit has recently been achieved through code development to allow efficient execution on PC clusters which has made possible today the extension to either three dimensions or unsteady analysis. In the next three to five years, realistic (SRL:3,4,?) three dimensional, unsteady analyses will be attempted, largely through the development of clustering technology to harness the power of commodity computing. In the last two years, the implementation of real fluids model in various research and production $\mathrm{CFD}$ codes has allowed significantly more realistic fluid properties to be represented in CFD simulations of rocket devices.

The current challenges of code and model development are, in order of MSFC priority, the Verification and Validation of existing CFD models and accurate models or simulations of turbulent mixing. There are more challenges, but these are the necessary foundation of any CFD simulation. Note that without $V \& V$, no real advancement can made in the code and model development area. 
2) Current design, state of the art practice

The current state of the art, in relation to the two major challenges defined above, is to maintain a stable of benchmark cases with which to perform regression testing as new versions and even new CFD programs are developed. This activity does not address verification at all and only addresses validation in the most rudimentary sense. Addition of new benchmark cases with new CFD code and model development is a rare event for most organizations, including NASA/MSFC. In most instances of CFD in practice, formal grid convergence assessment is not included. In terms of mixing models, it appears from the authors experience that two-equation models are the most prevalent. Most benchmark suites include only cases for which the two equations models have been calibrated, thus guaranteeing that a real world assessment of mixing prediction accuracy is unknown.

Advantages of a validated CFD-based methodology

The primary advantage of a verified and validated CFD-based methodology is that the CFD practitioner is aware of what the tool can and more importantly cannot, model accurately. There are a large number of 'new and improved' turbulence models developed in the last several decades and meaningful evaluation of these models for application to the simulation of rockets is not possible without a verified CFD implementation and a series of well-chosen validation cases with which to perform the assessment.

3) Grouping of CUIP tasks to show how they relate to the essential elements of the focus area

In the code and model development area, an overall strategy is being pursued by NASA/MSFC. That strategy is to identify a path to the production codes in use at NASA/MSFC for all tasks that purport to obtain validation data, develop models, or investigate rocket engine related physics.

Only a figure can capture the interactions which lead to NASA benefit. I am constructing this figure.

4) Highlight- a key task of parallel experiment/calculation

Dahm: well defined path to production codes. Computations follow.

Merkle(Unsteady mixing and ignition): integrated experimental/computational attack. Only recently is a path to production codes evident. 


\section{Summary}

The organization and operation of the CUIP TCA VI in its effort to supply advanced TCA/injector design tools for use in the Constellation project. The vision for the work acknowledged the need for improved design tools and pointed out five Focus Areas for the VI's involvement. Four of these are areas constitute the VI's scope. These areas, where there are significant are TCA design requirements or constraints are ignition, performance, thermal environments and combustion stability. The fifth area, CFD code development, validation and verification defines the approach to providing the new tools.

The SSME development program was used to make the case for the need for the new tools. The potential and obstacles for CFD becoming the basis for thee new design tool were pointed out. The key obstacle was shown to be lack of appropriate code validation. Key processes to facilitate execution of the vision, such as hierarchical decomposition and the SRL concept, were discussed. Validation at the so called unit problem level was shown to be a critical, and typically lacking, component of validation.

The final portion of the paper involved discussion of each of the five Focus Areas born out of the vision. The discussion consisted of background and justification for work in the area, the state of the art in that area for rockets and the CUIP research focus in that area. Each Focus Area section was concluded by brief discussion of each task in that area. 


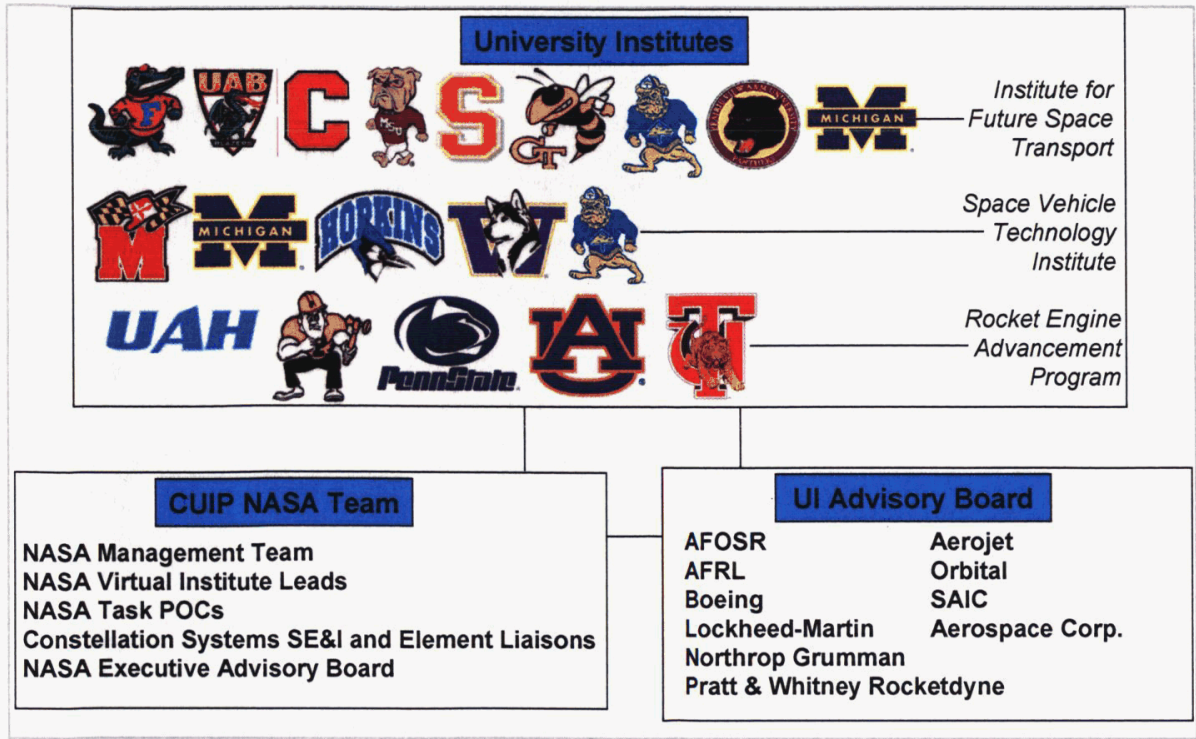

Figure 1. The CUIP Organization Depicting Contractual Institutes

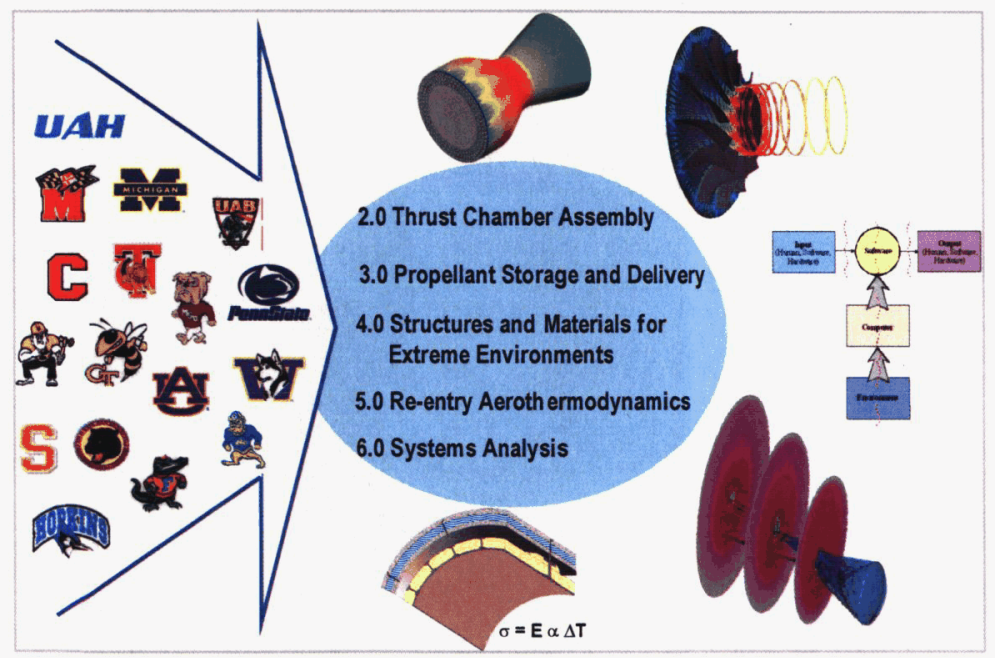

Figure 2. The CUIP Virtual Institutes 


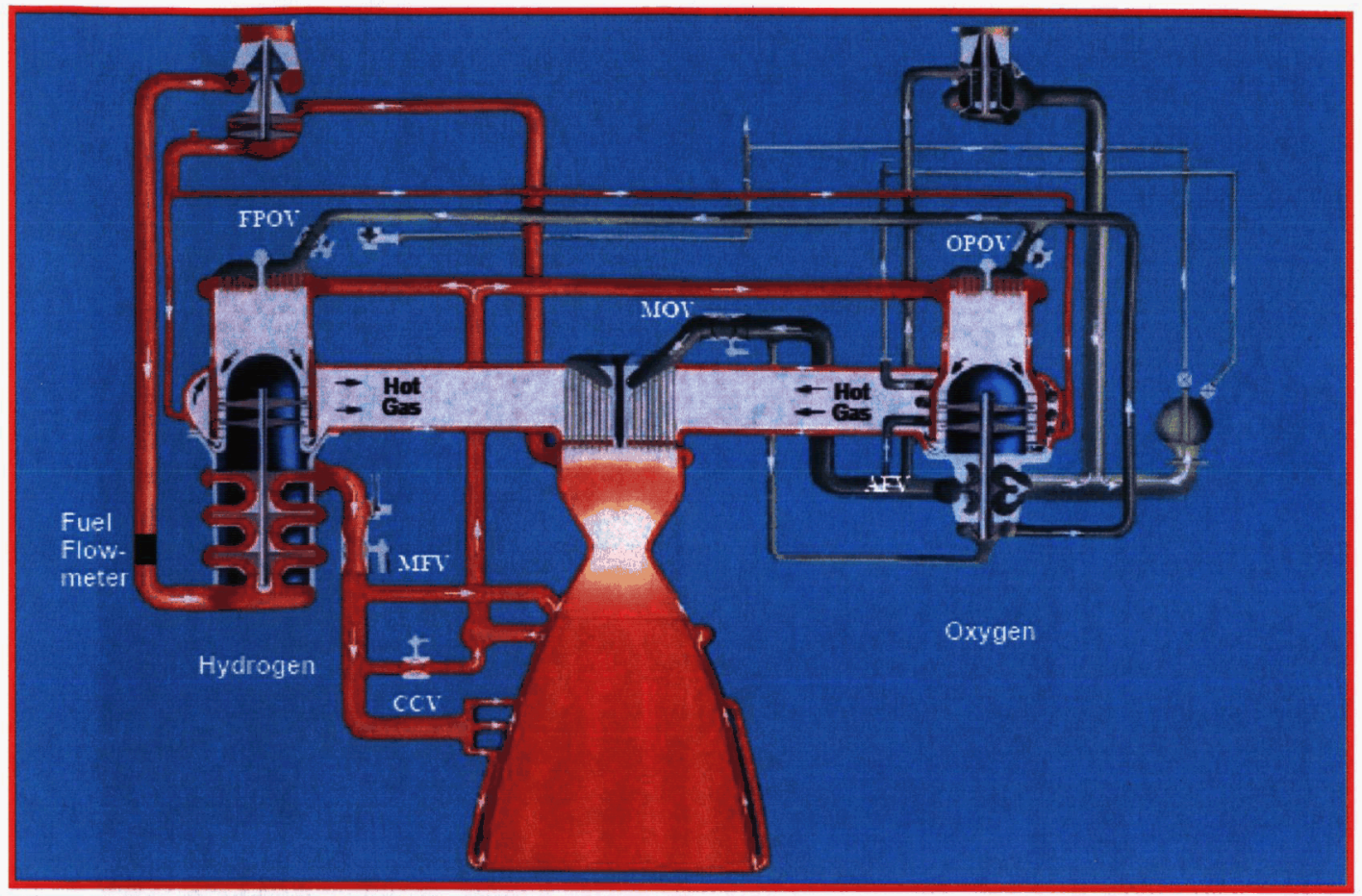

Figure 3. Notional view of rocket engine thrust chamber assembly

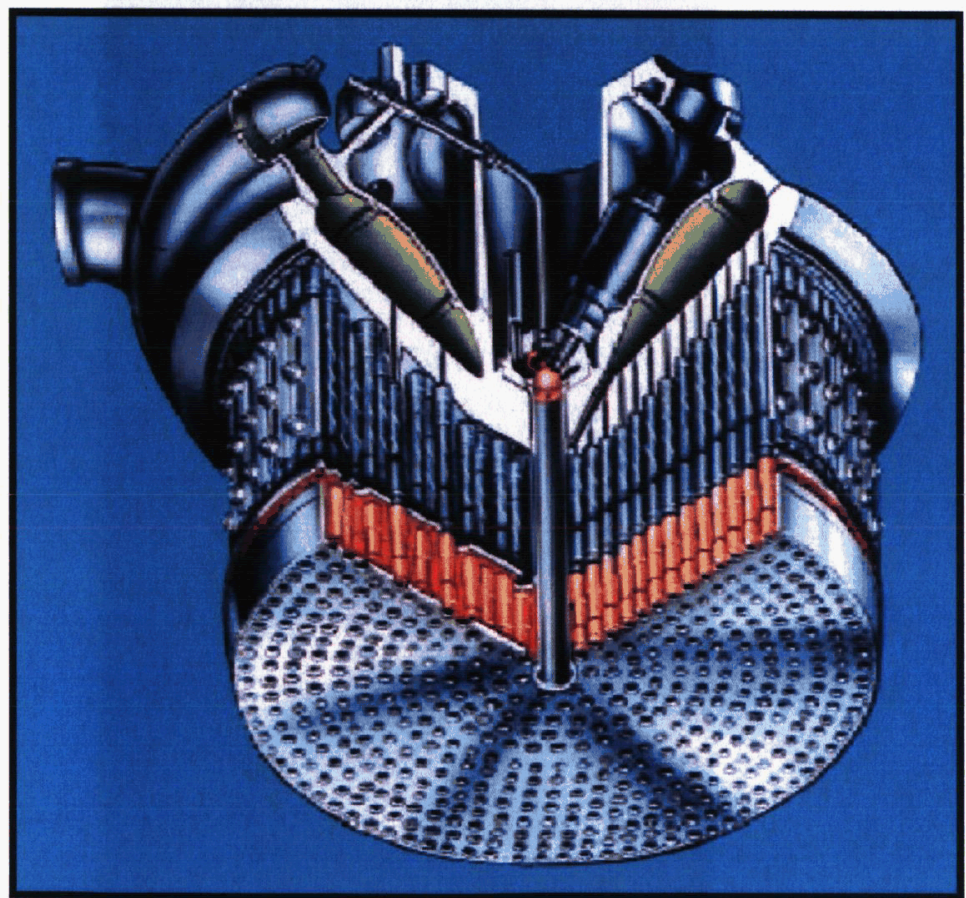

Figure 4. Rocket engine injector. 


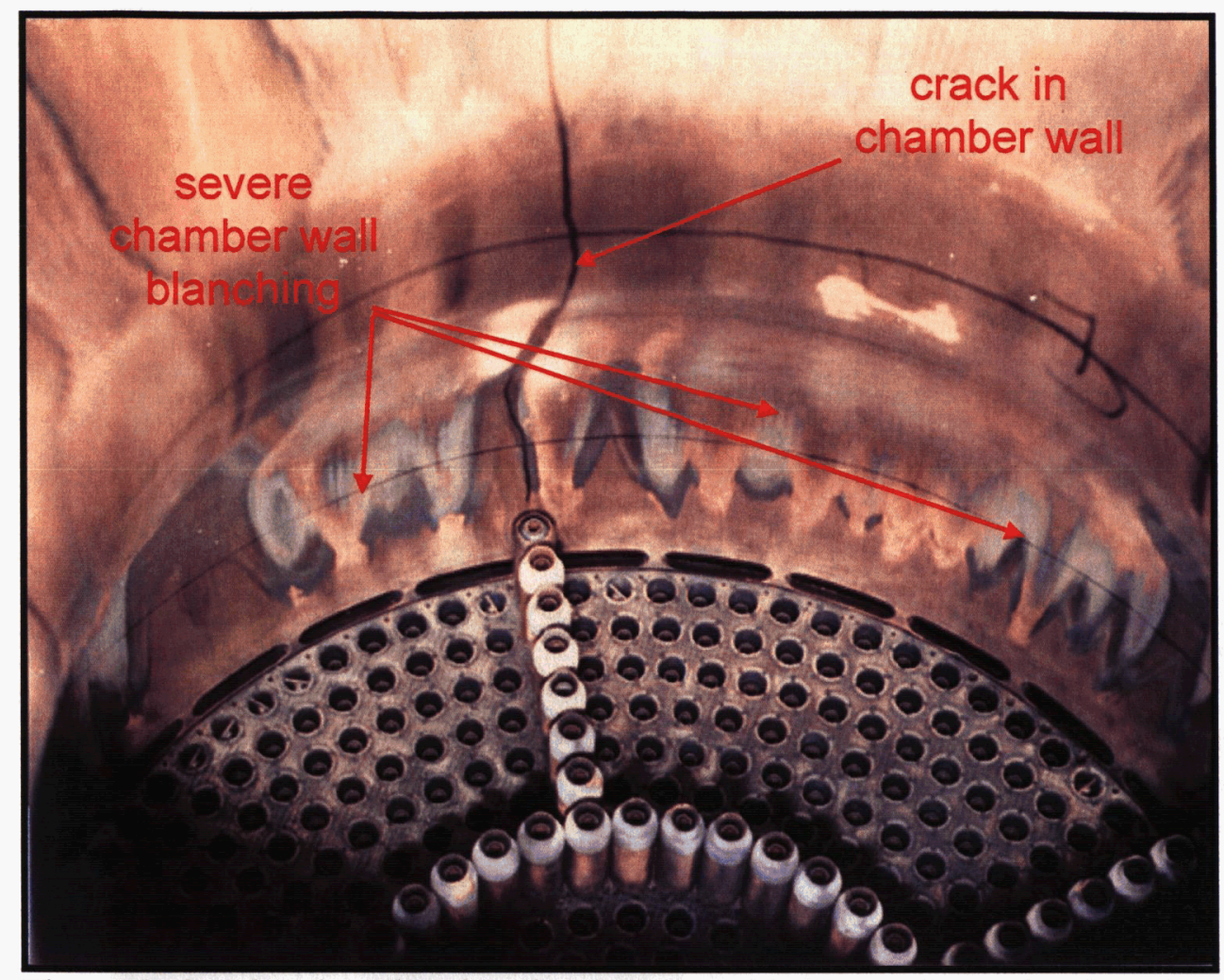

Figure 5. Combustion chamber damage caused by three-dimensional environments.

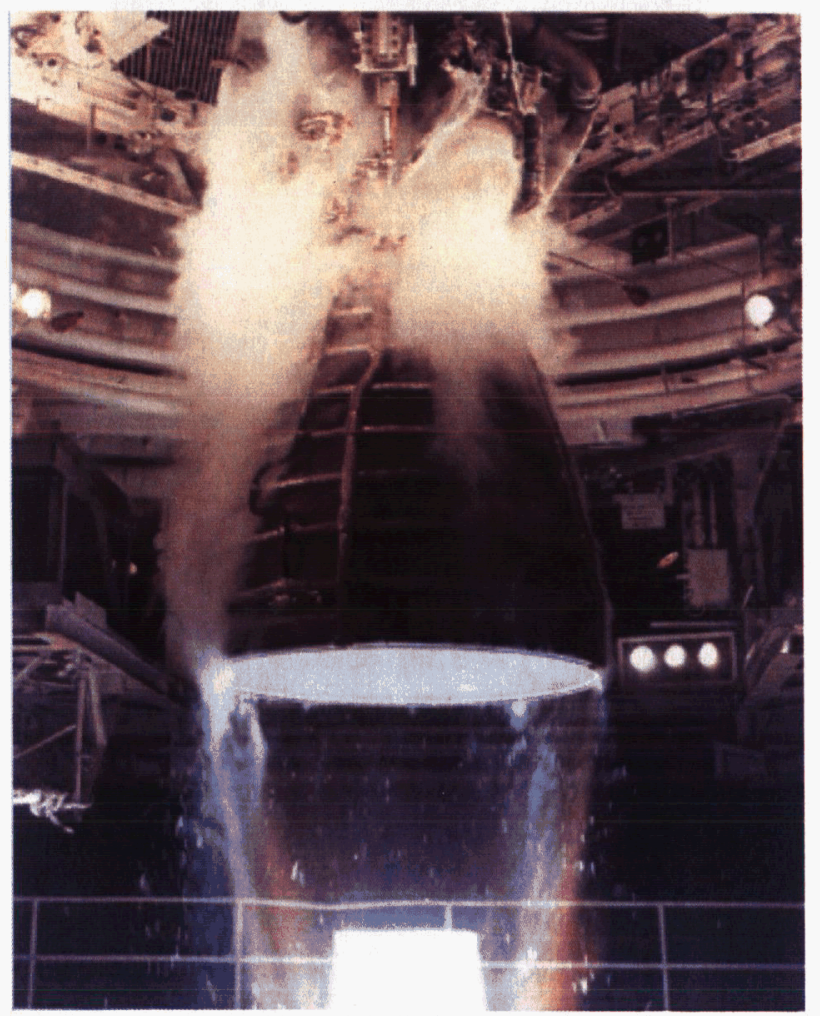

Figure 6. SSME test firing. 


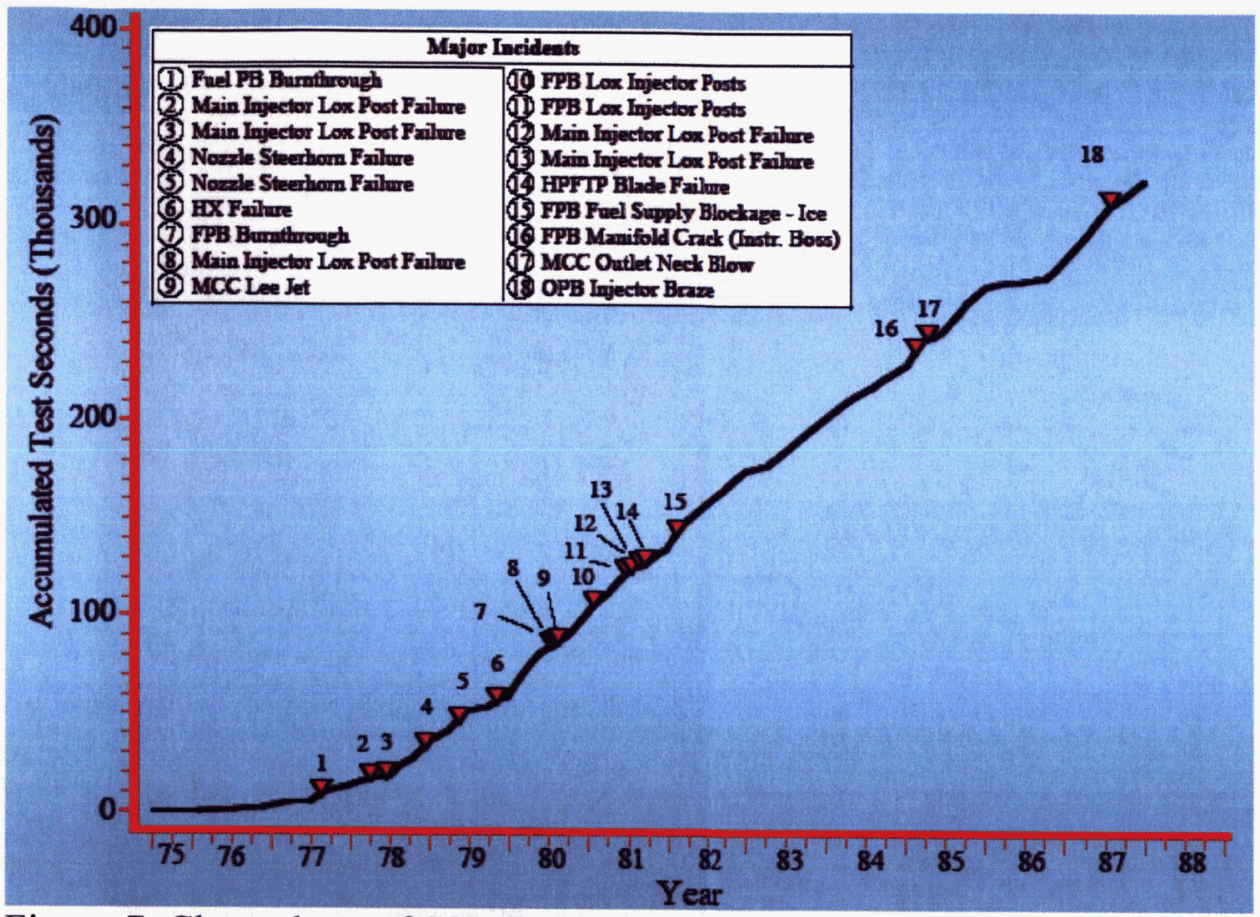

Figure 7. Chronology of SSME Combustion Devices major Incidents

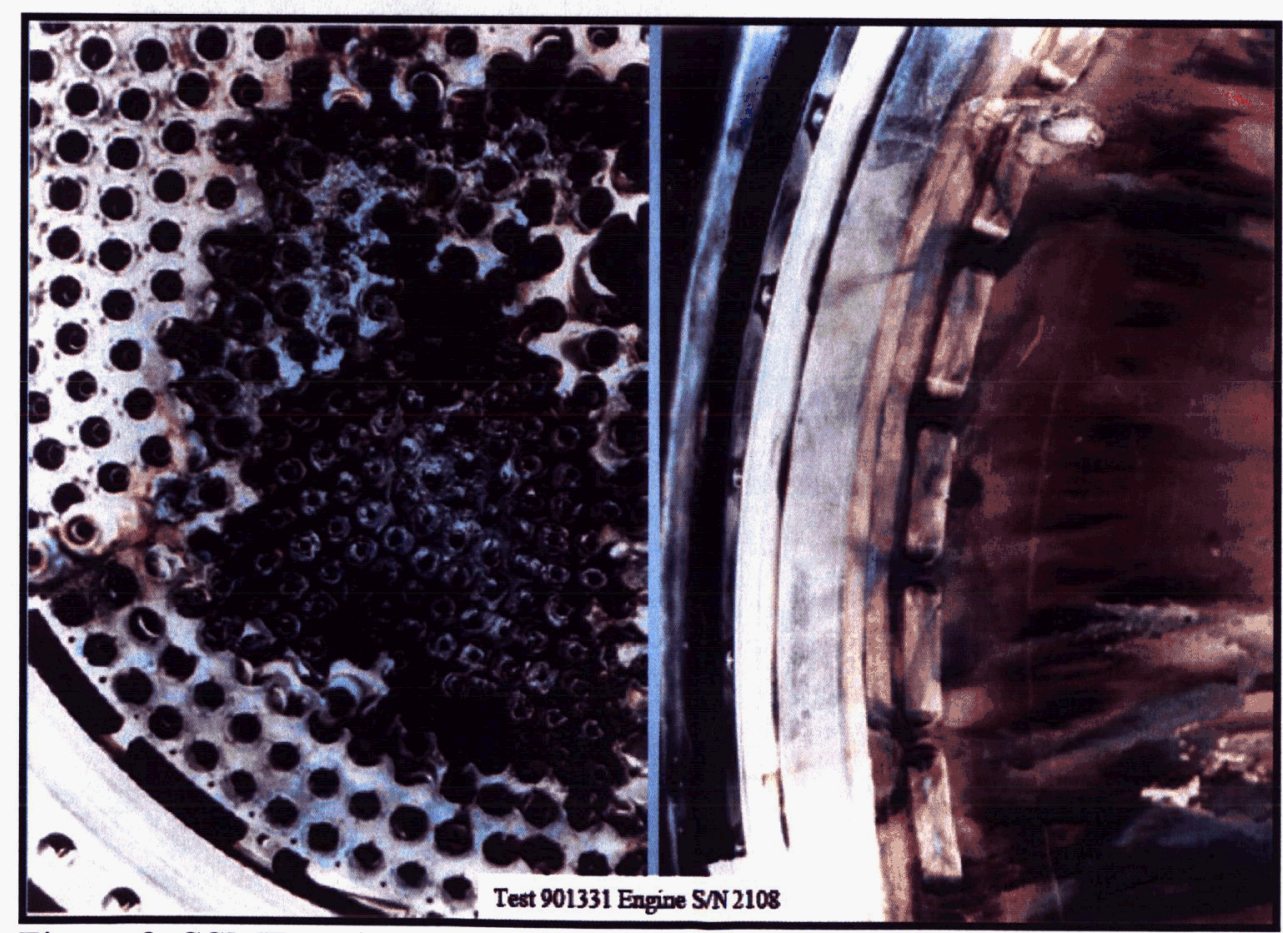

Figure 8. SSME Main Injector (left) and Combustion Chamber (right) damage during a 1981 engine test. 


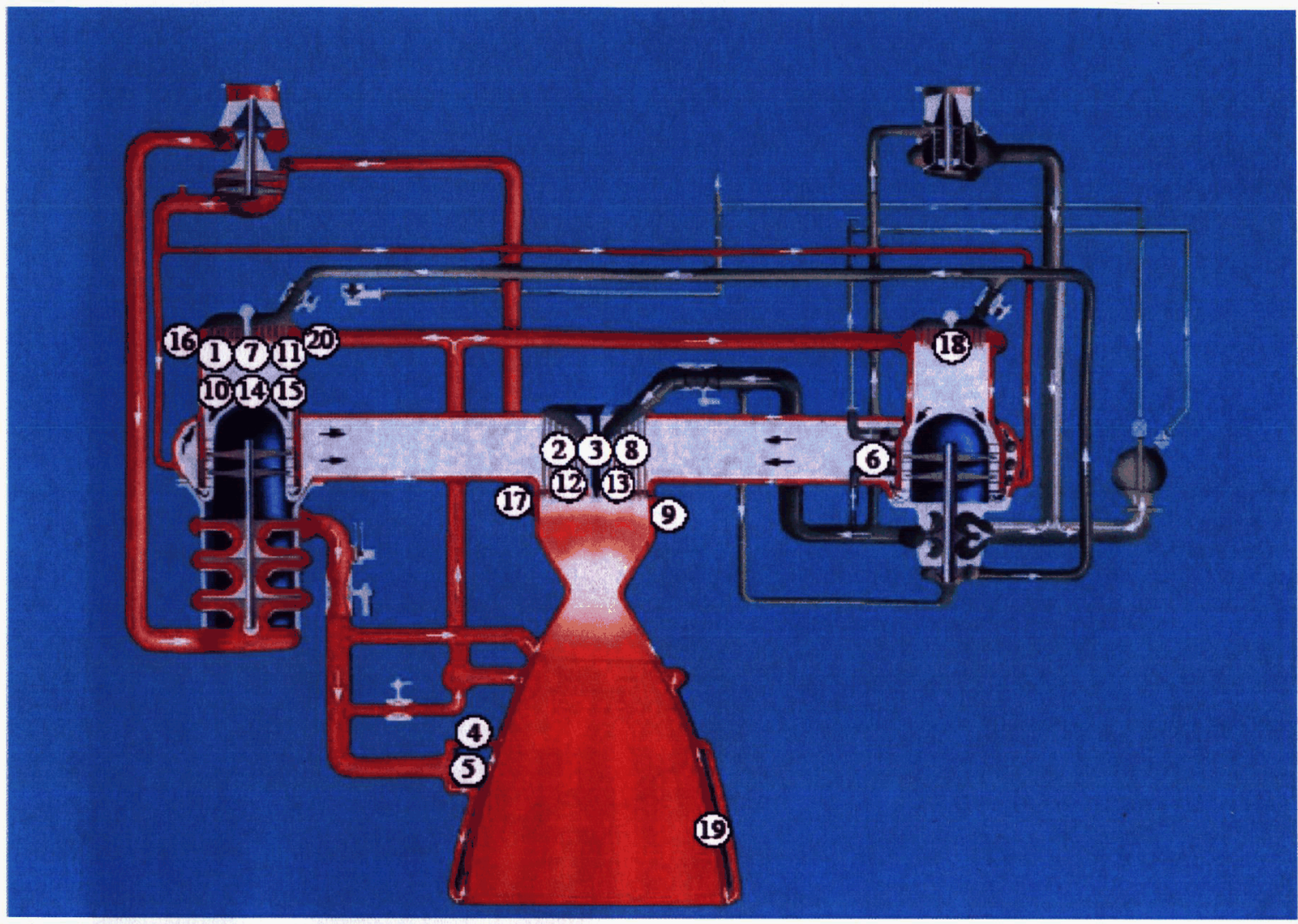

Figure 9. SSME major combustion devices failures mapped by location.

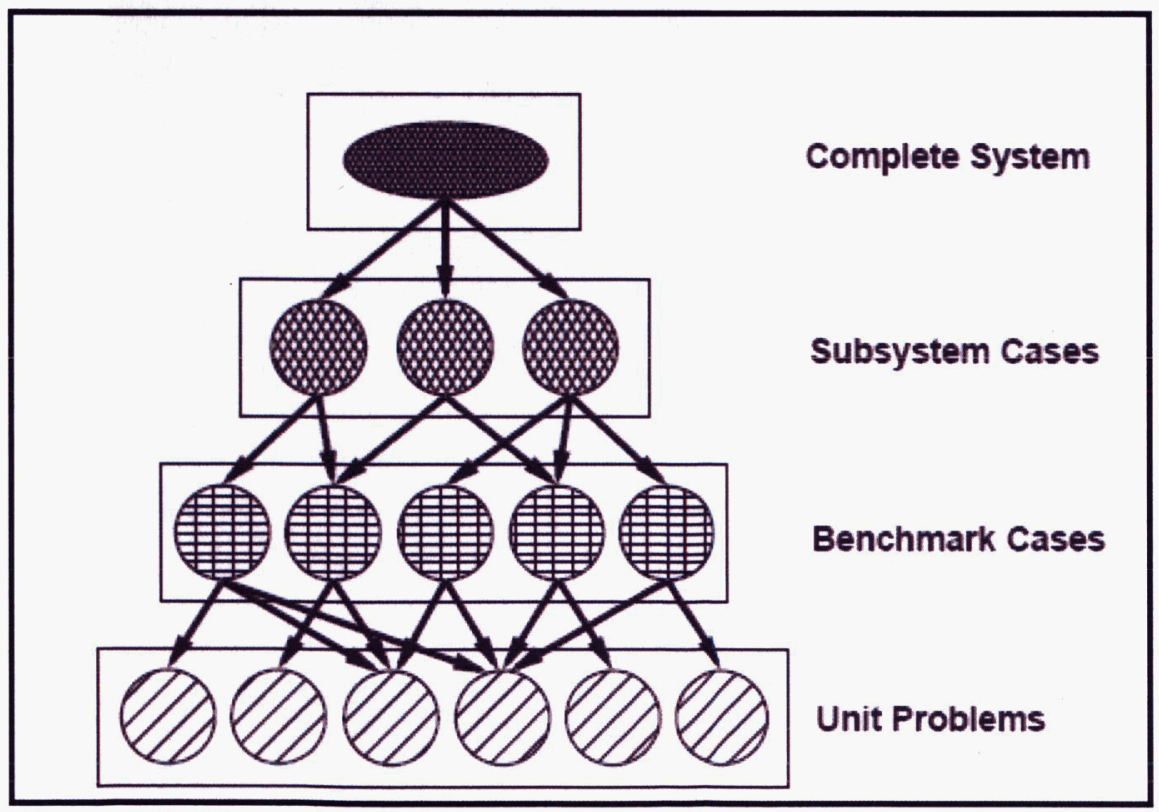

Figure 10. Hierarchical decomposition of a complex system. 


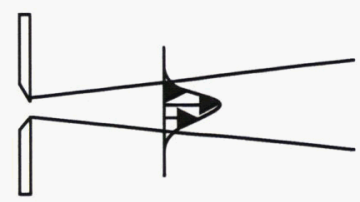

Shear

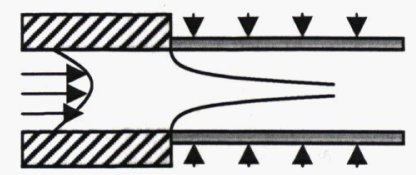

Heat Transfer

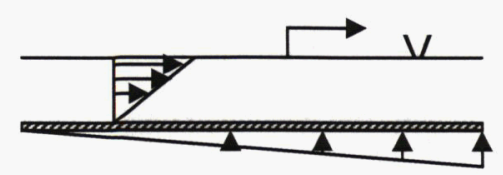

Mass Transfer

Figure 11. Example injector unit problems

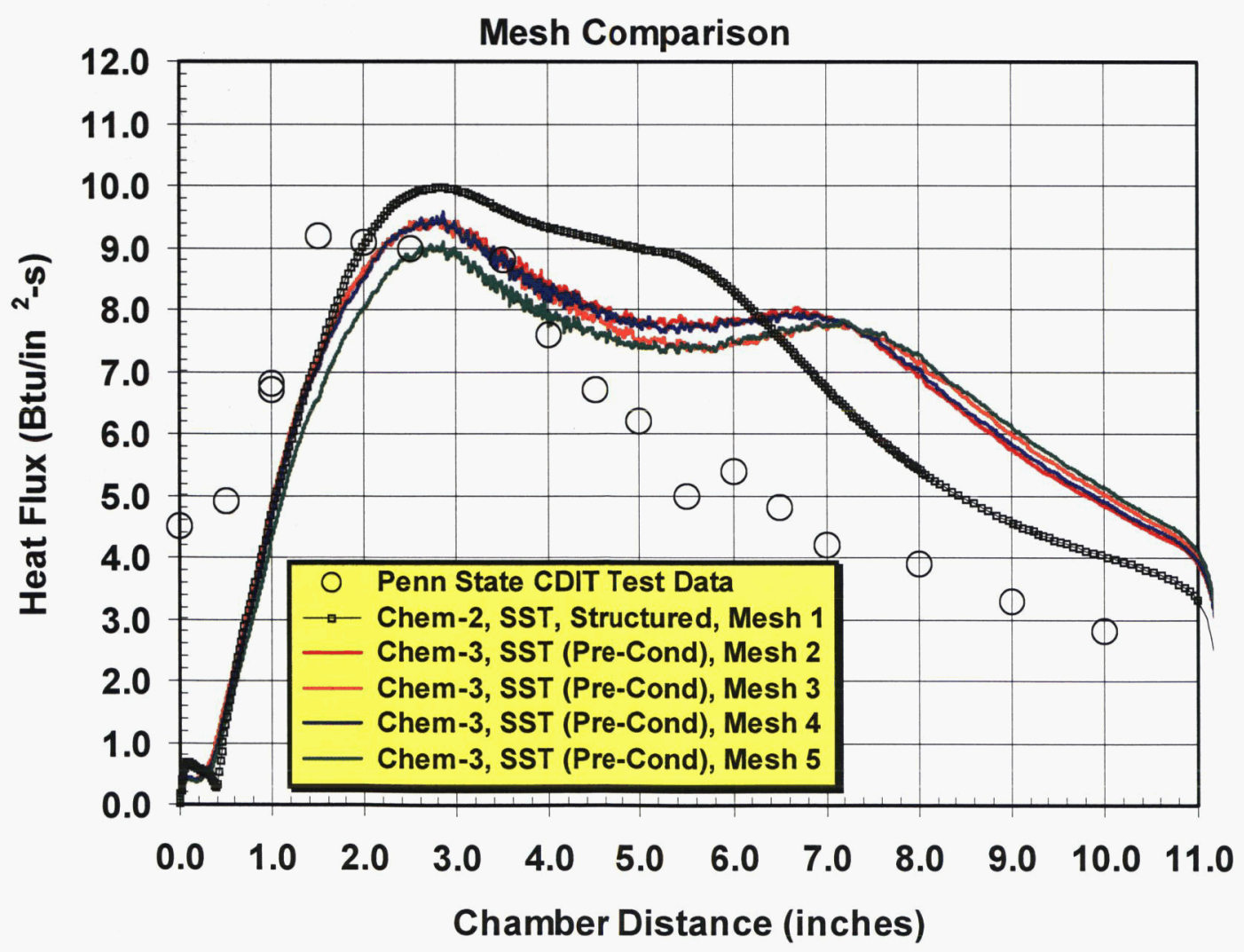

Figure 12. CFD solution compared to experimental data for a $\mathrm{GO} 2 / \mathrm{GH} 2$ single element injector. 


\begin{tabular}{|c|c|c|c|}
\hline Level & Fidelity & Robustness & Accuracy \\
\hline$\overline{0}$ & $\begin{array}{l}\text { Extremely simple physics, } \\
\text { boundary conditions and } \\
\text { geometry }\end{array}$ & $\begin{array}{l}\text { Have not completed any } \\
\text { simulations }\end{array}$ & \begin{tabular}{l}
\multicolumn{1}{c}{ Verification } \\
Not evaluated other than \\
historical quality of simulation \\
tool
\end{tabular} \\
\hline 1 & $\begin{array}{l}\text { Reasonably precise } \\
\text { geometry and boundary } \\
\text { conditions, extremely } \\
\text { simple physics }\end{array}$ & $\begin{array}{l}\text { Have completed some } \\
\text { simulations }\end{array}$ & $\begin{array}{l}\text { Unit Problem } \\
\text { Qualitative agreement with } \\
\text { existing results of related } \\
\text { problems }\end{array}$ \\
\hline 2 & $\begin{array}{l}\text { Reasonably precise physics } \\
\text { with extremely simple } \\
\text { boundary conditions and } \\
\text { geometry }\end{array}$ & $\begin{array}{l}\text { Simulations with proven } \\
\text { convergence and } \\
\text { conservation }\end{array}$ & \begin{tabular}{l}
\multicolumn{1}{c}{ Unit Problem } \\
Quantitative agreement with \\
existing results of related \\
problems
\end{tabular} \\
\hline 3 & $\begin{array}{l}\text { Reasonably precise } \\
\text { physics, boundary } \\
\text { conditions and geometry }\end{array}$ & $\begin{array}{l}\text { Simulations with proven } \\
\text { convergence, } \\
\text { conservation and grid } \\
\text { independence }\end{array}$ & $\begin{array}{l}\text { Benchmark (model) Problem } \\
\text { Qualitative agreement of relevant } \\
\text { measures for one representative } \\
\text { problem }\end{array}$ \\
\hline 4 & $\begin{array}{l}\text { Reasonably precise } \\
\text { physics, completely precise } \\
\text { boundary conditions and } \\
\text { as-built geometry }\end{array}$ & $\begin{array}{l}\text { Fire and Forget }(95 \%+) \\
\text { simulations with } \\
\text { convergence, } \\
\text { conservation and grid } \\
\text { independence }\end{array}$ & $\begin{array}{l}\text { System \& Subsystem } \\
\text { Qualitative agreement of relevant } \\
\text { measures over parametric space } \\
\text { of actual problems }\end{array}$ \\
\hline 5 & $\begin{array}{l}\text { Completely precise } \\
\text { physics, completely precise } \\
\text { boundary conditions and } \\
\text { as-built geometry }\end{array}$ & \begin{tabular}{|l} 
Fire and Forget $(95 \%+)$ \\
simulations with \\
convergence, \\
conservation and grid \\
independence plus the \\
ability to complete 100 or \\
more problems within 3 \\
weeks
\end{tabular} & $\begin{array}{l}\text { System \& Subsystem } \\
\text { Quantitative agreement of } \\
\text { relevant measures over } \\
\text { parametric space of actual } \\
\text { problem }\end{array}$ \\
\hline
\end{tabular}

Table 1. SRL matrix for simulation evaluation. 


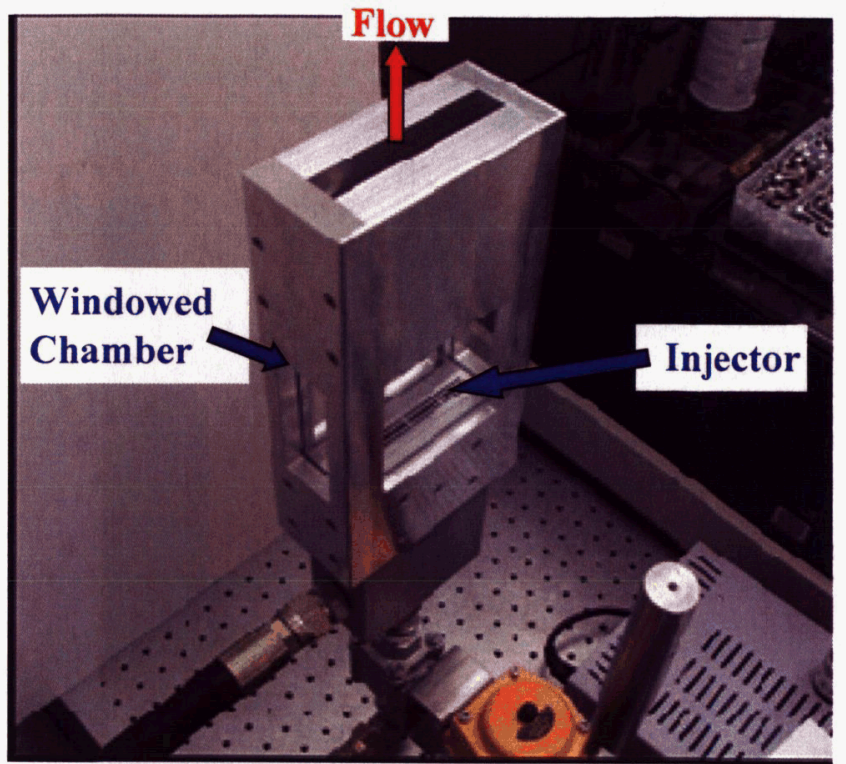

Figure 13. Two-dimensional test article for gas/gas transient mixing experiments.

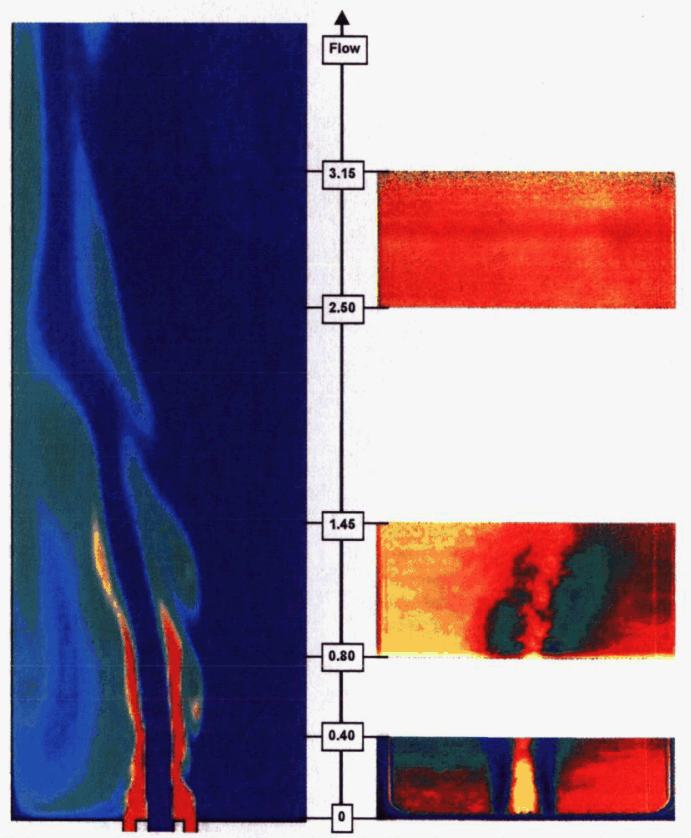

Figure 14. Computational (left) and experimental (right) results from gas/gas transient mixing simulations 


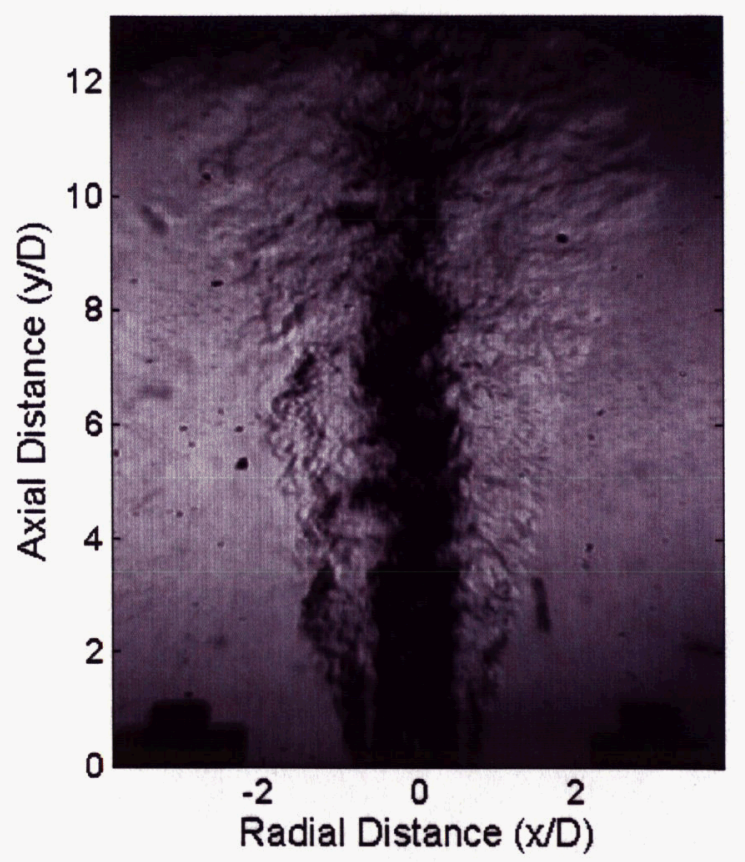

Figure 15. High-speed Schlieren image of an unconfined shear coaxial jet with liquid nitrogen and gaseous helium

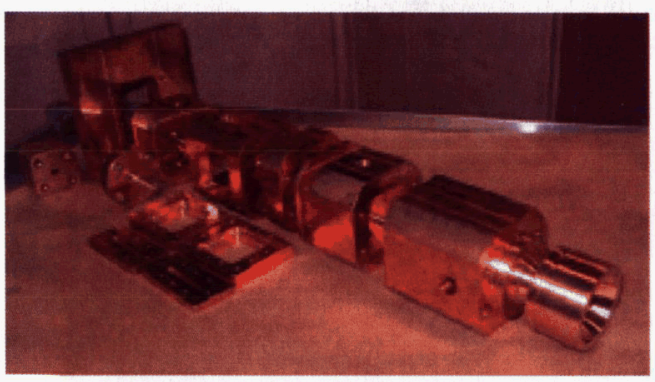

Figure 16. University of Michigan Single Element Injector Experiment 


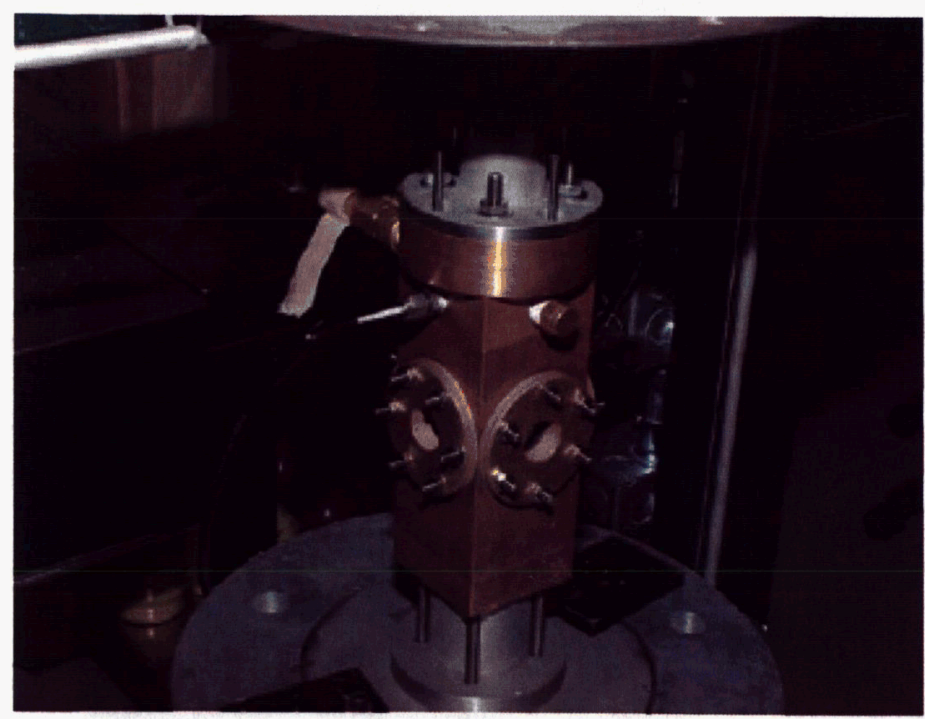

Figure 17. Optically accessible chamber at the University of Florida
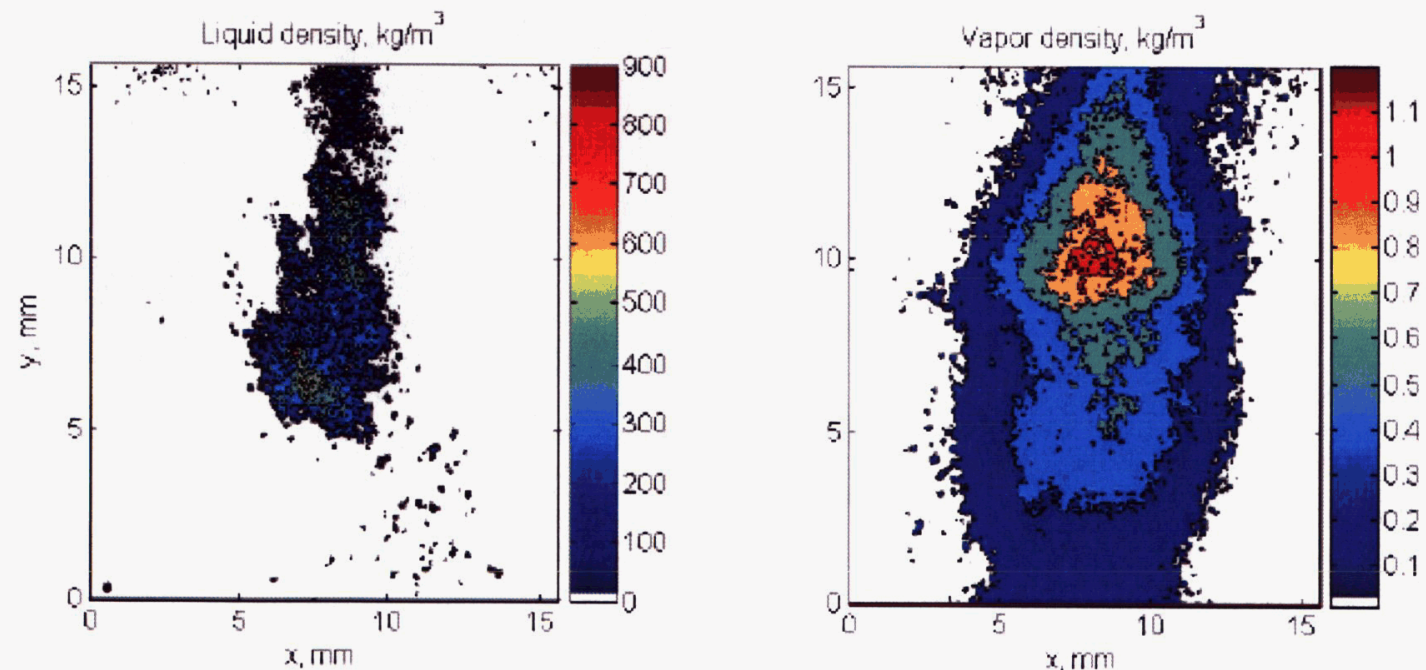

Figure 18. Liquid and vapor phase distributions of a coaxial jet at $20 \mathrm{~atm}$. 


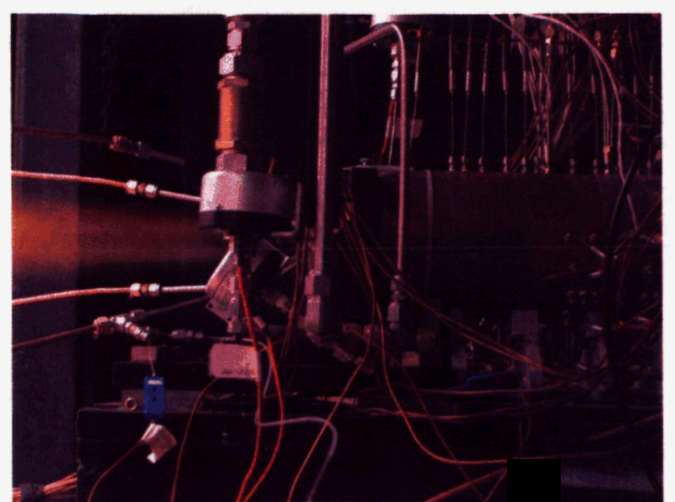

Figure 19. Hot fire test of a single element injector at Penn State University

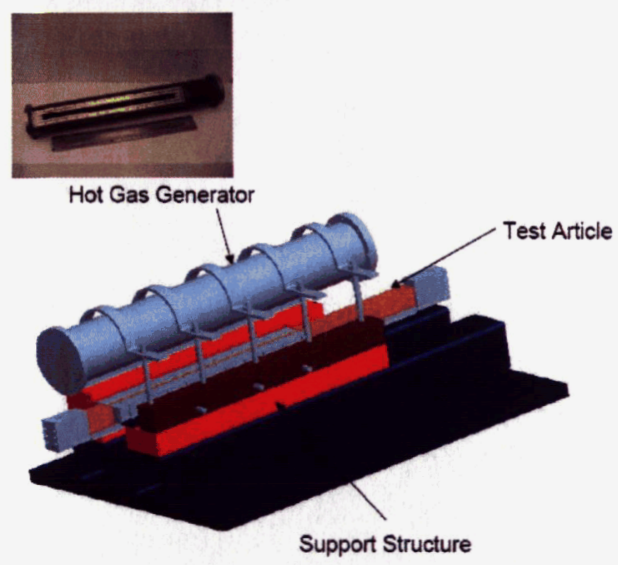

Figure 20: High Aspect Ratio Heat Exchanger Test Setup

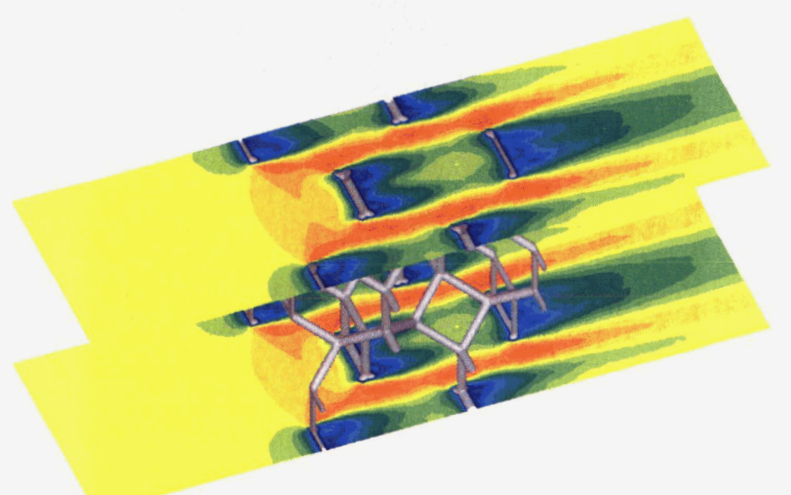

Figure 21: CFD Analysis of a cell of a foam filled heat exchanger 


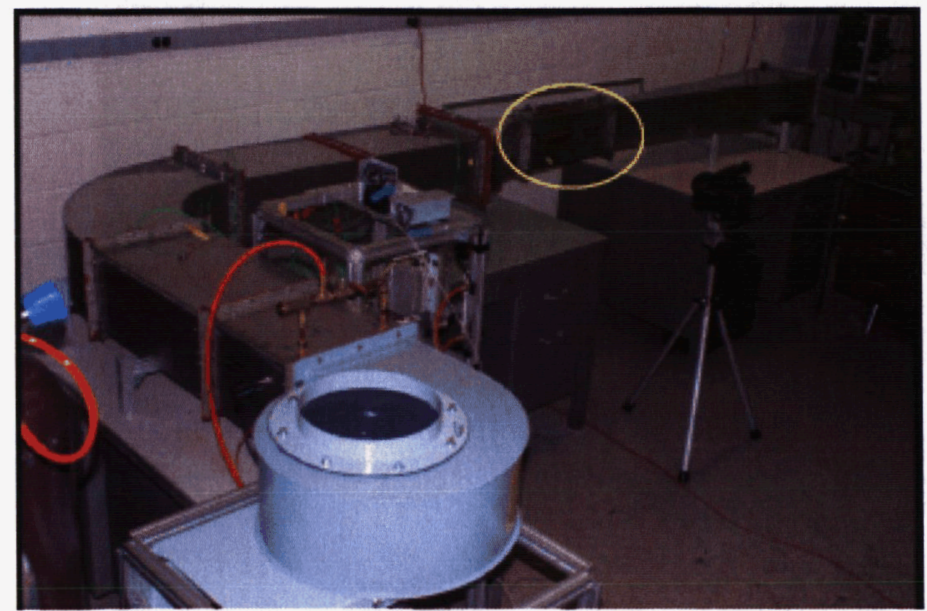

Figure 22: University of Maryland Film Cooling Experiment

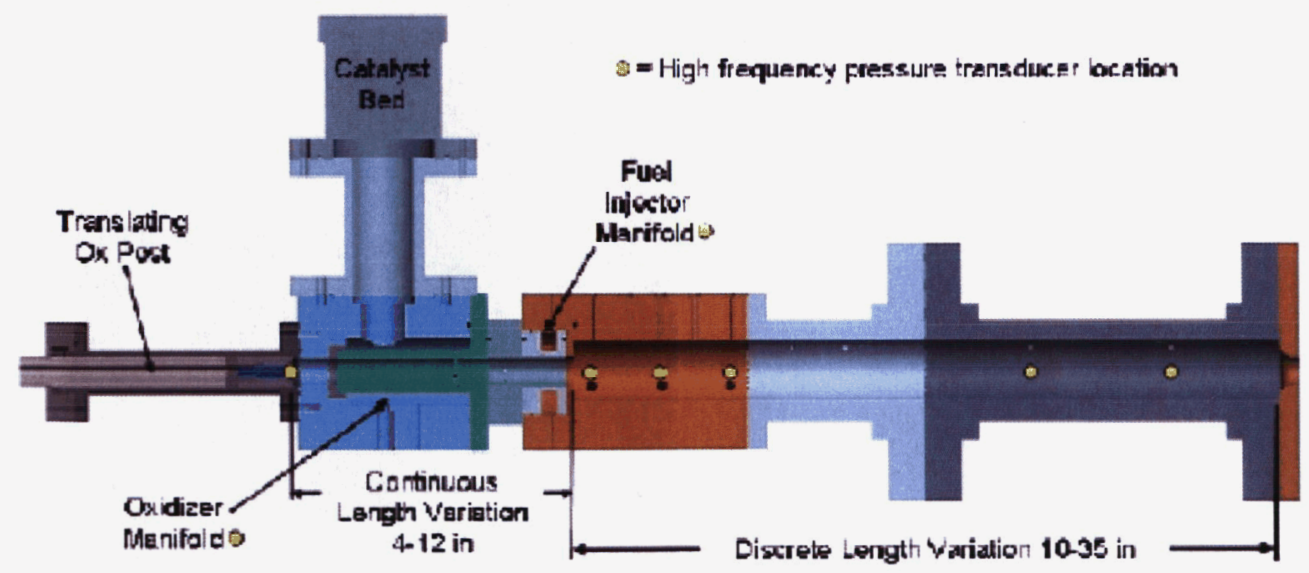

Figure 23. Model of Purdue test rig with variable injector and chamber lengths 


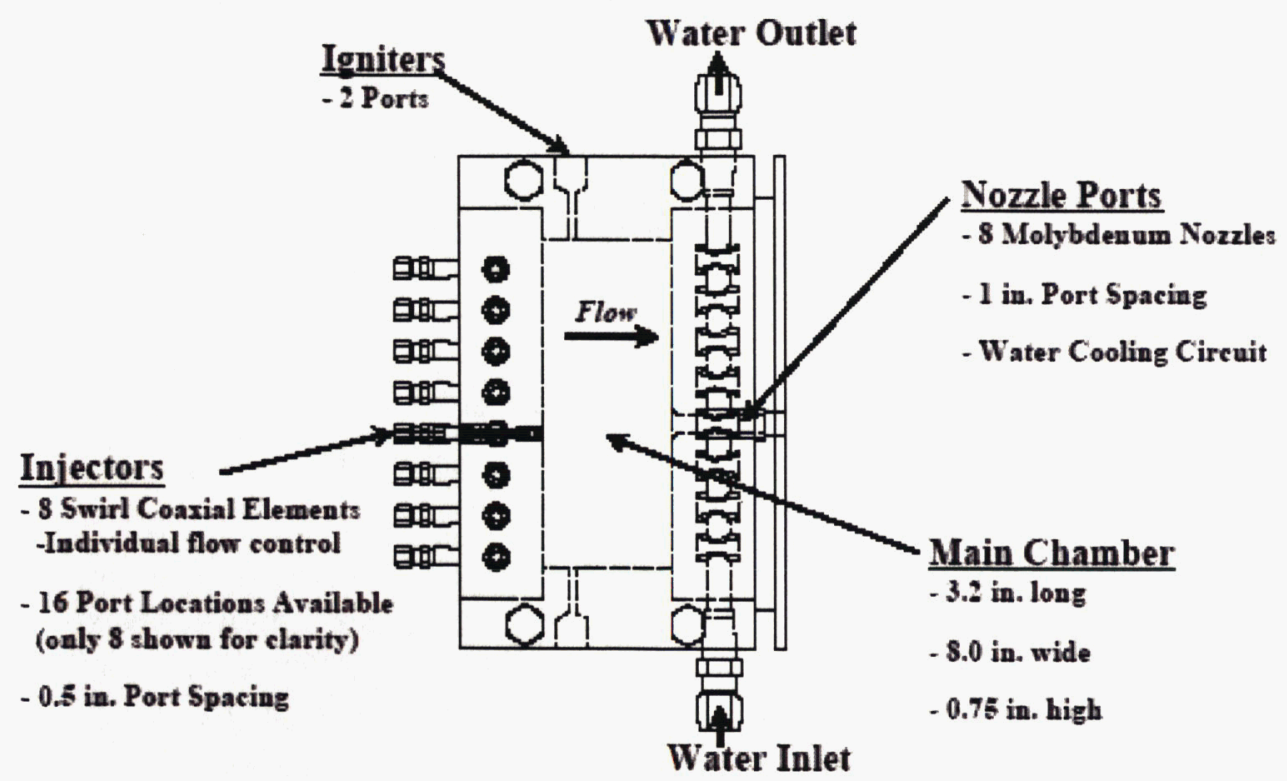

Figure 24. Schematic of the multi-element chamber for instability studies
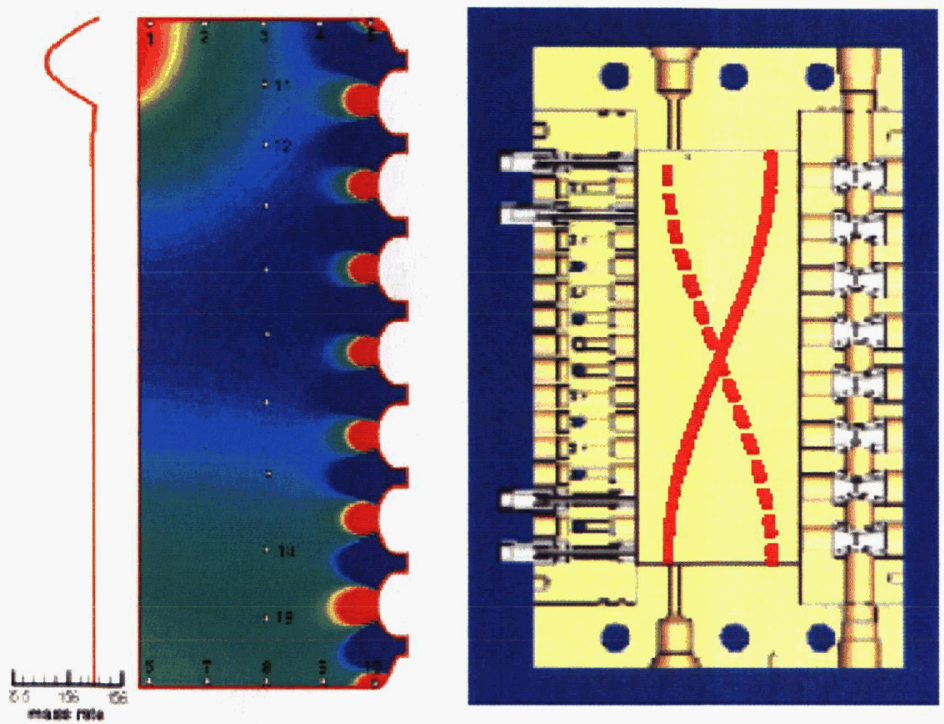

Figure 25. CFD calculation done to support multi-element rig design 


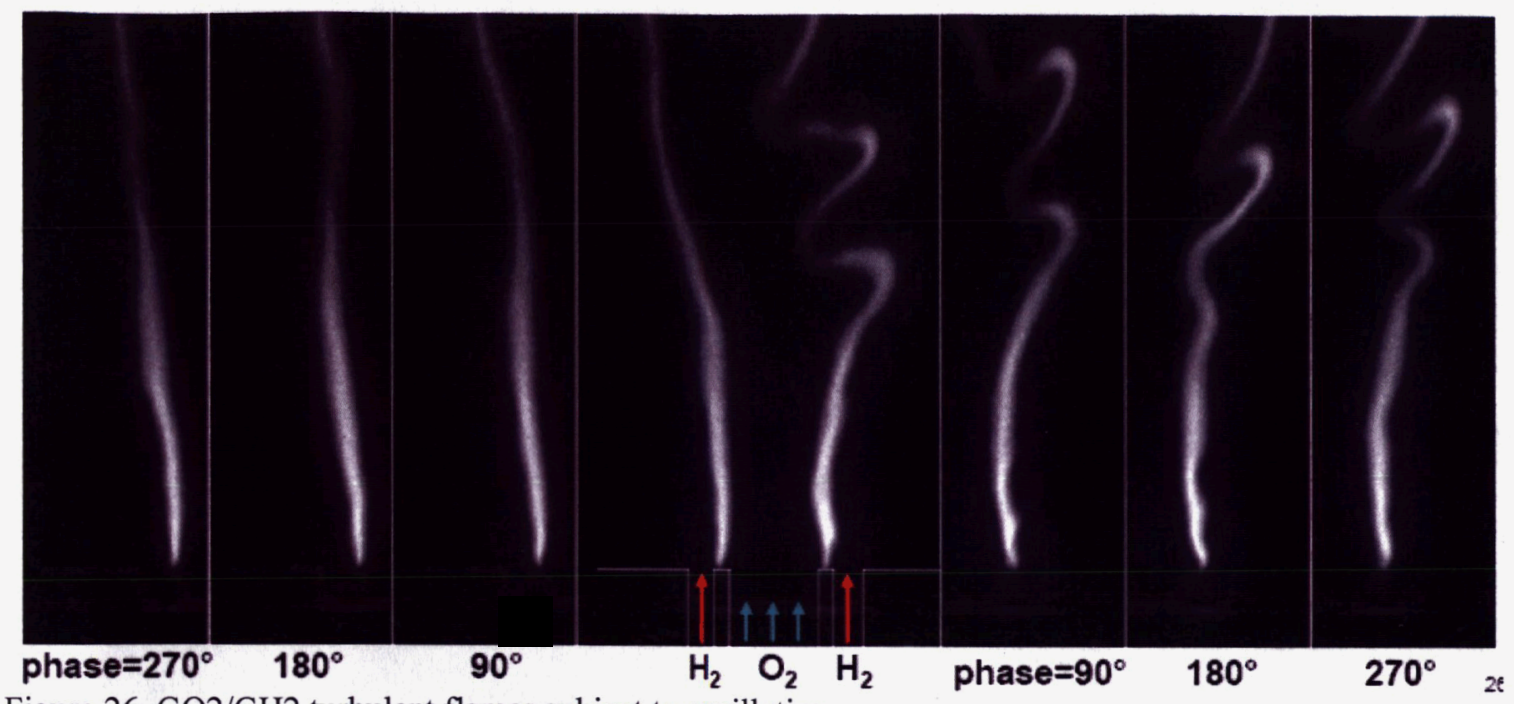

Figure 26. GO2/GH2 turbulent flames subject to oscillation. 


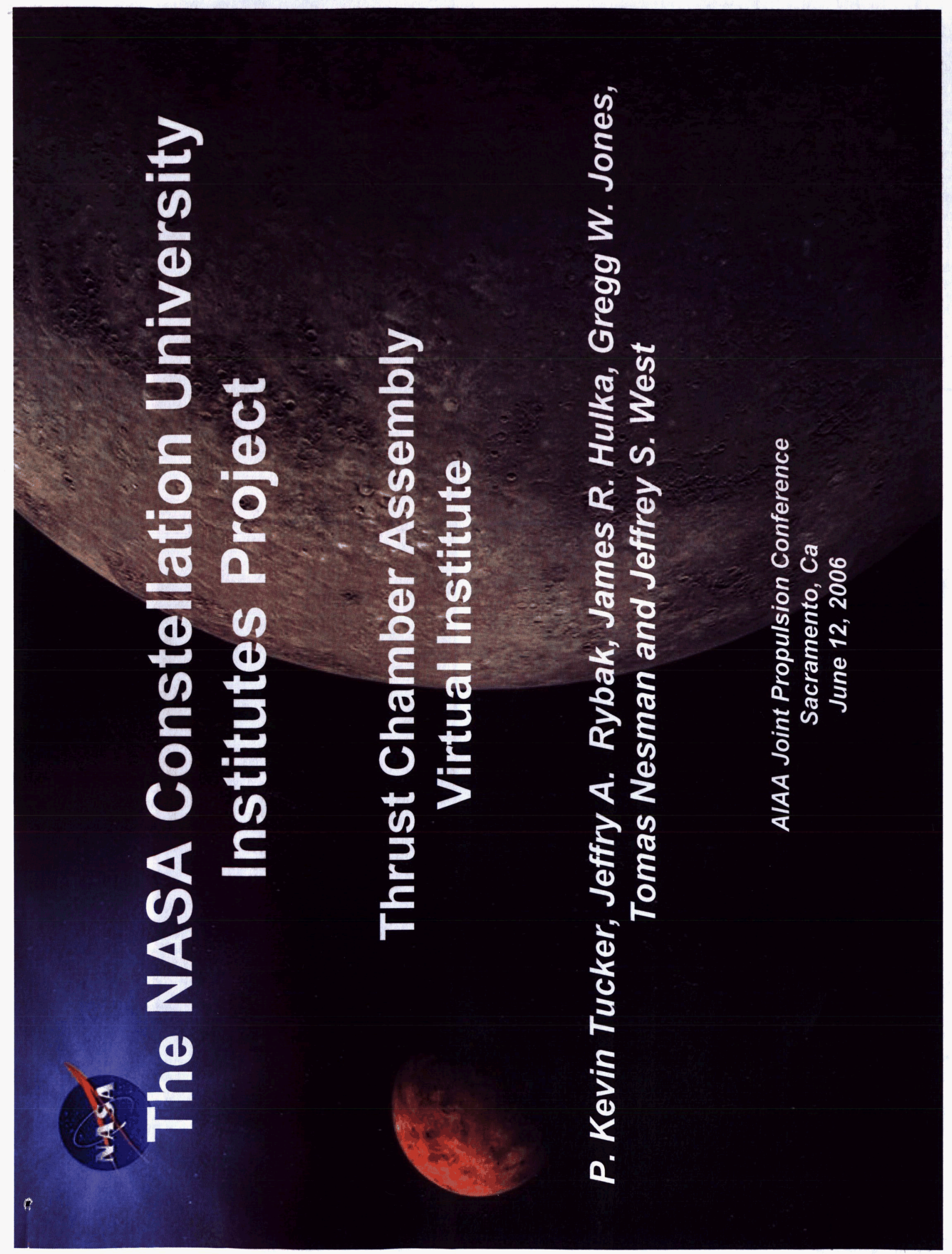



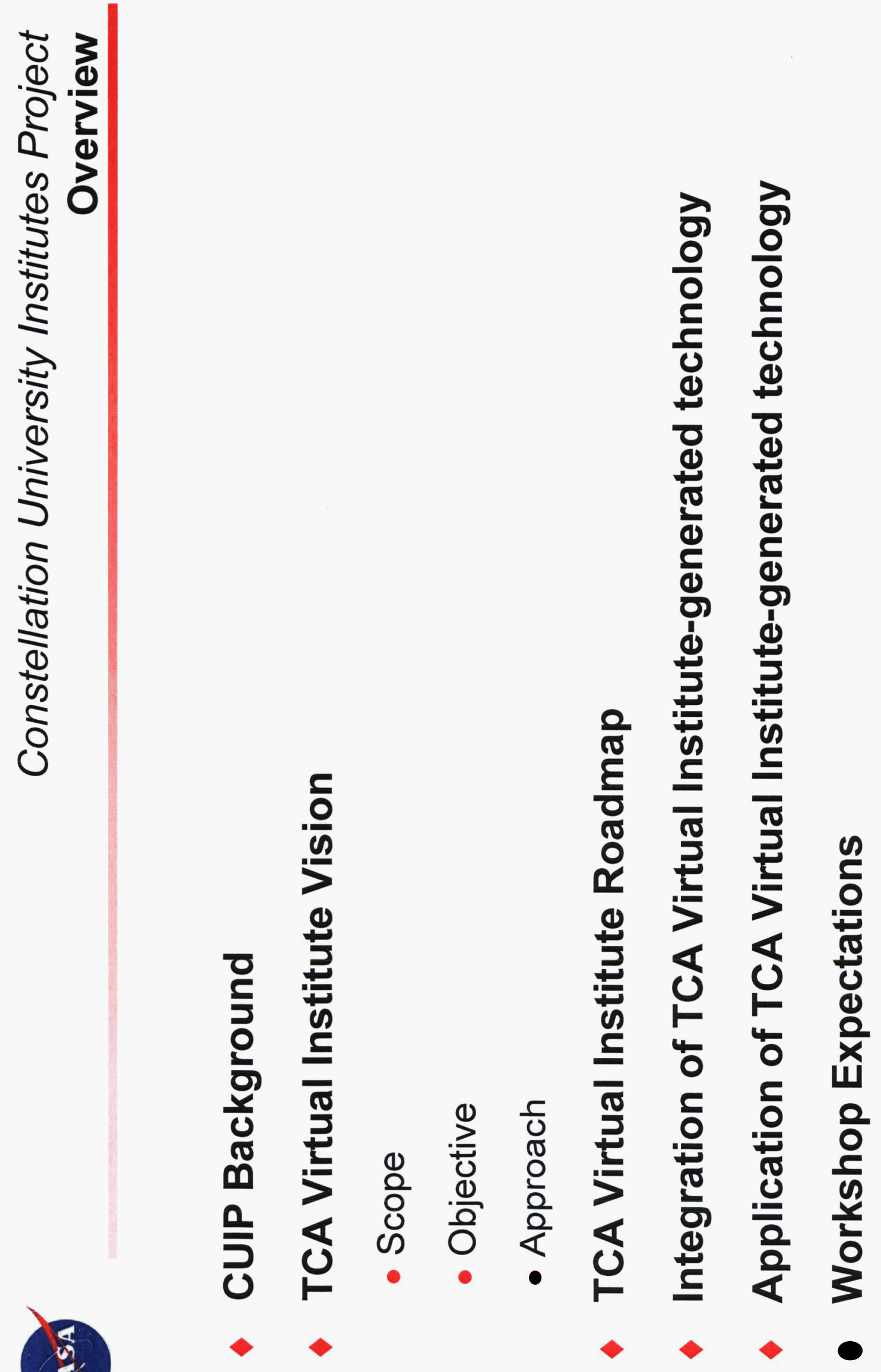


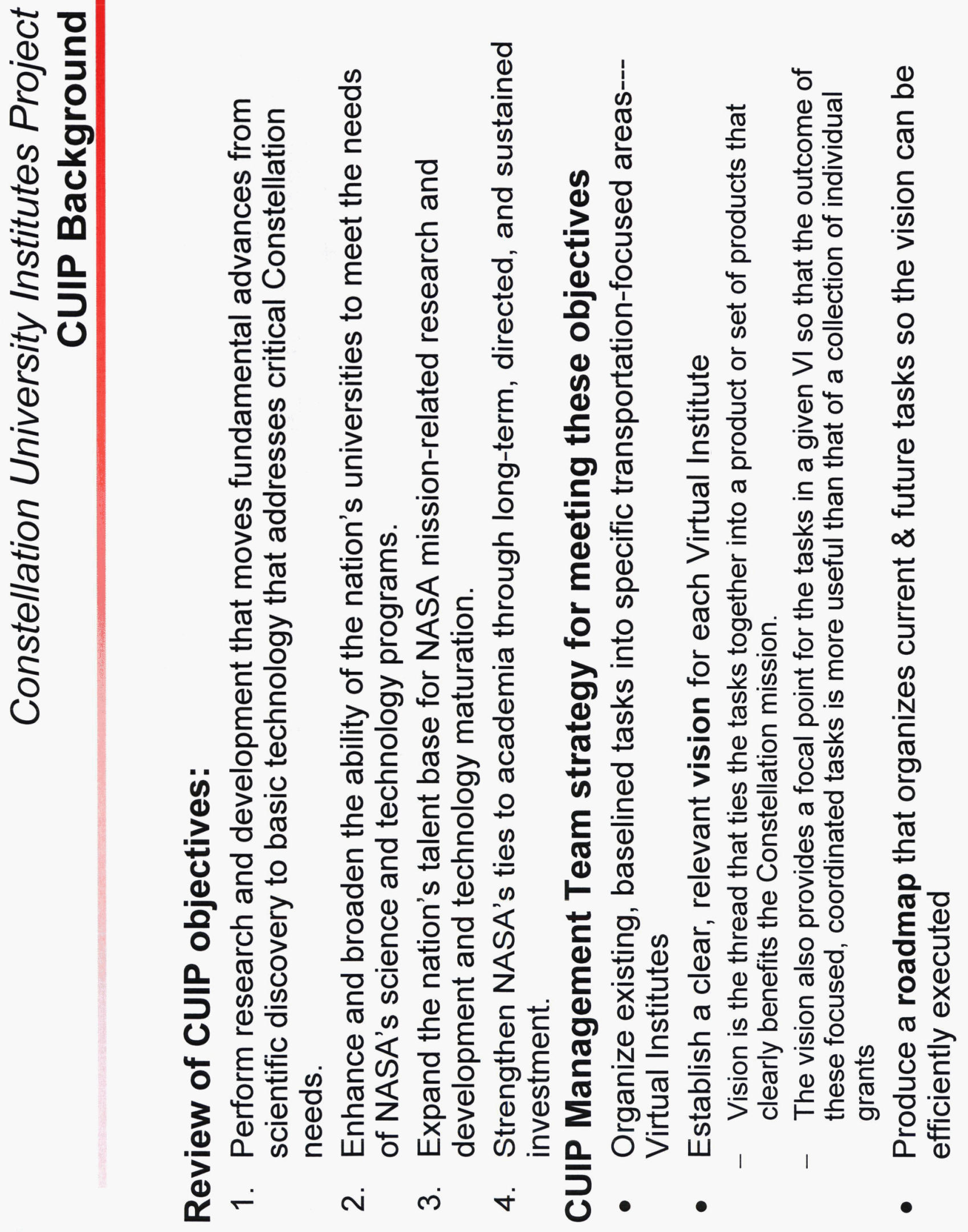



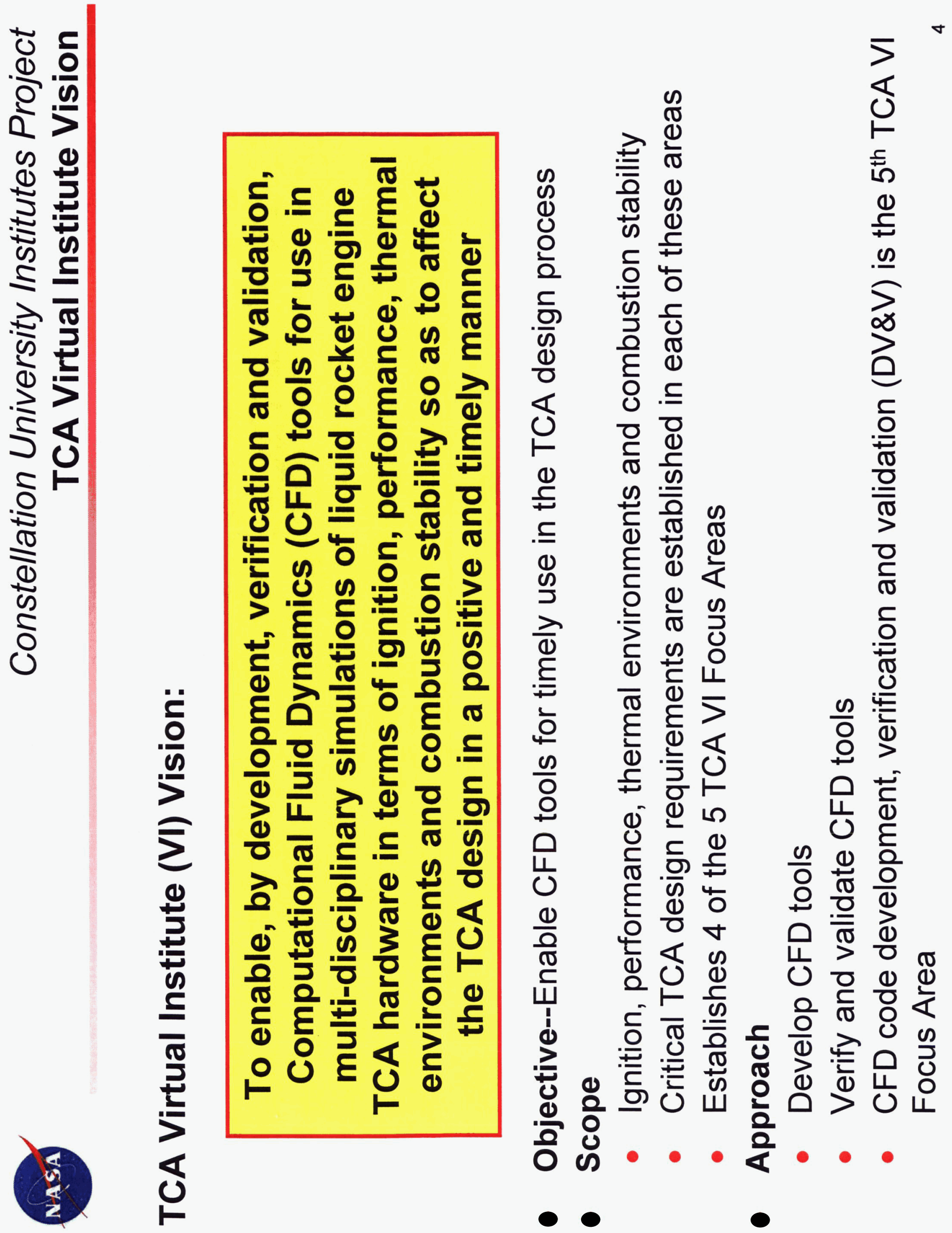


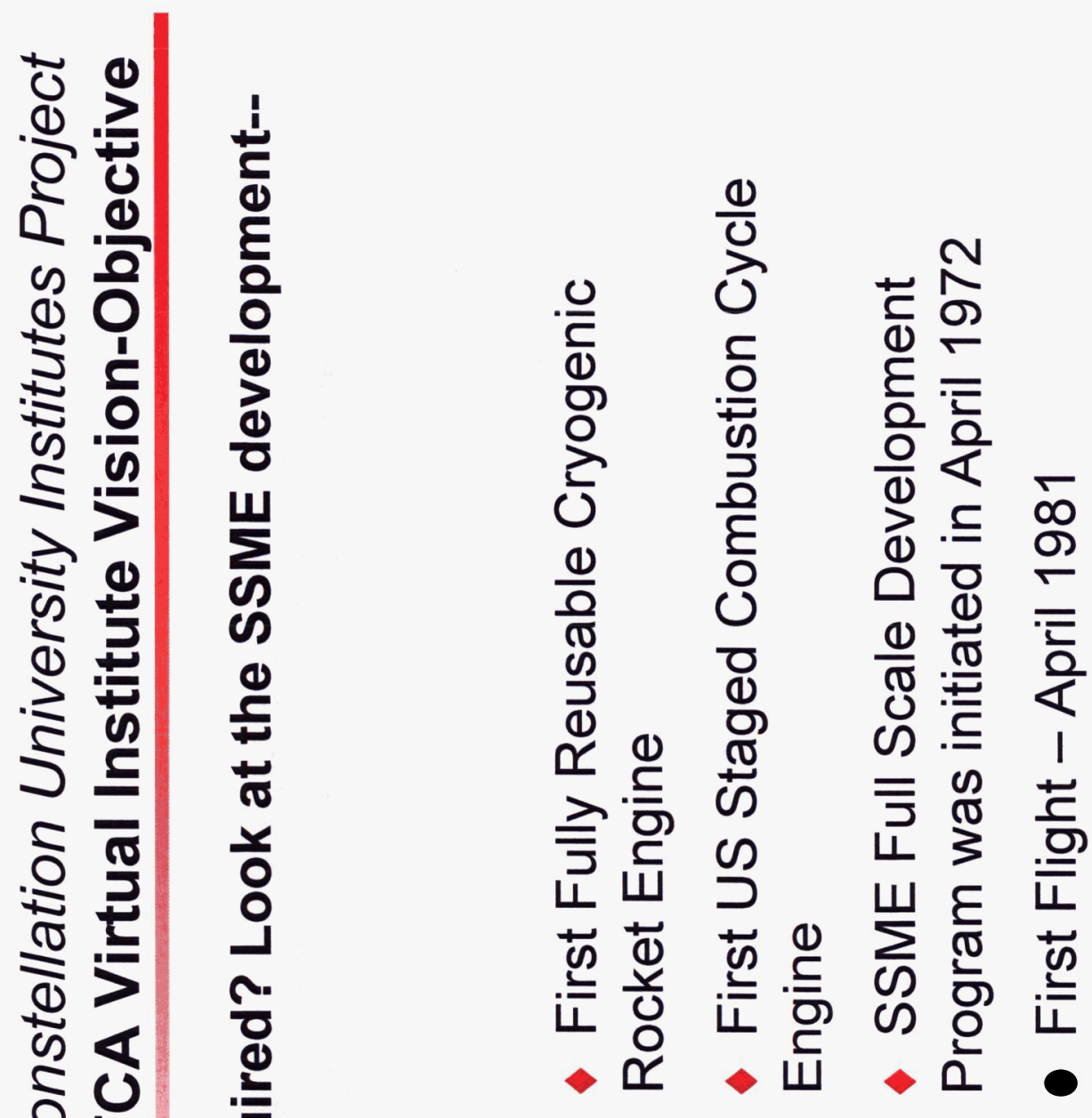



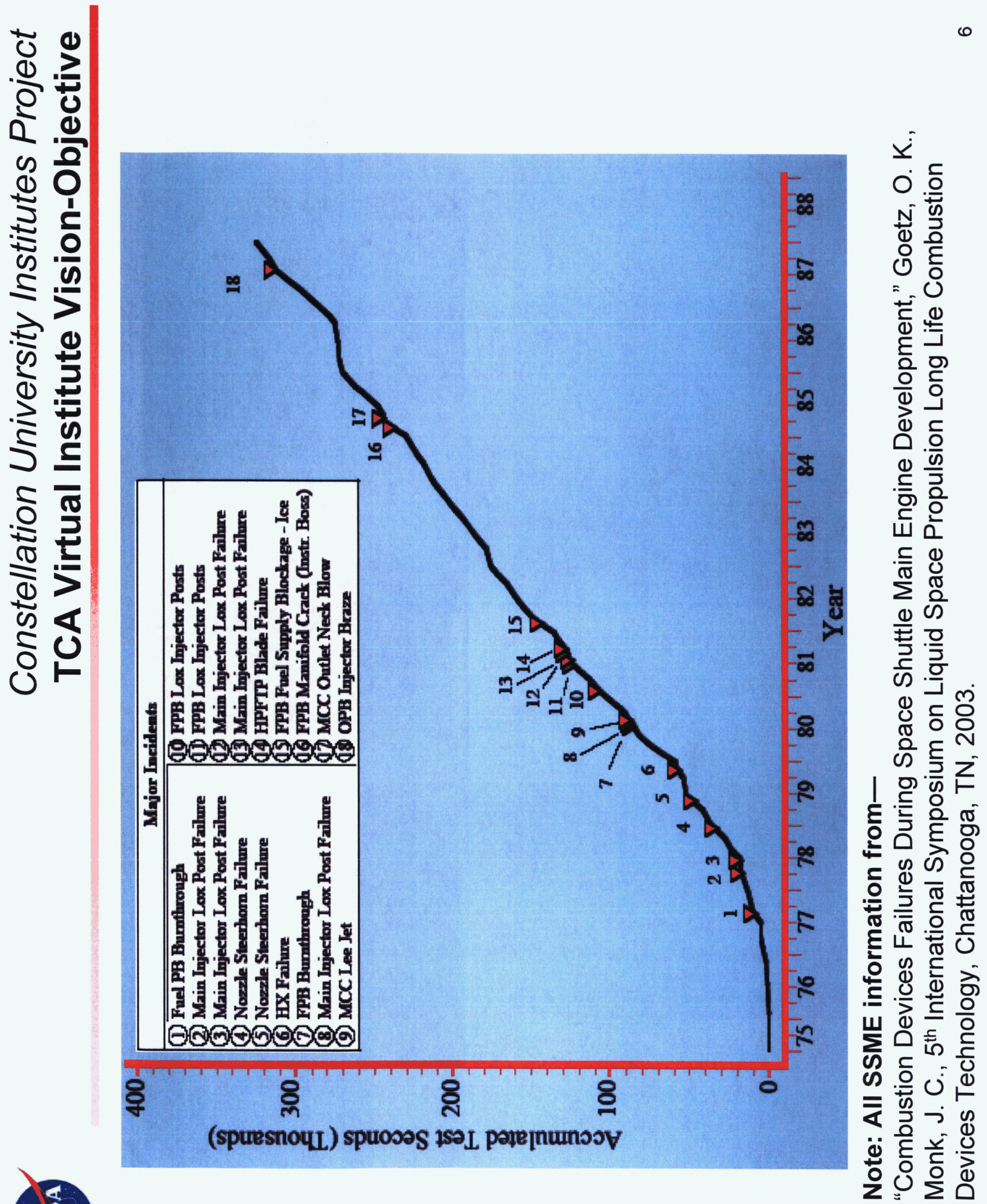


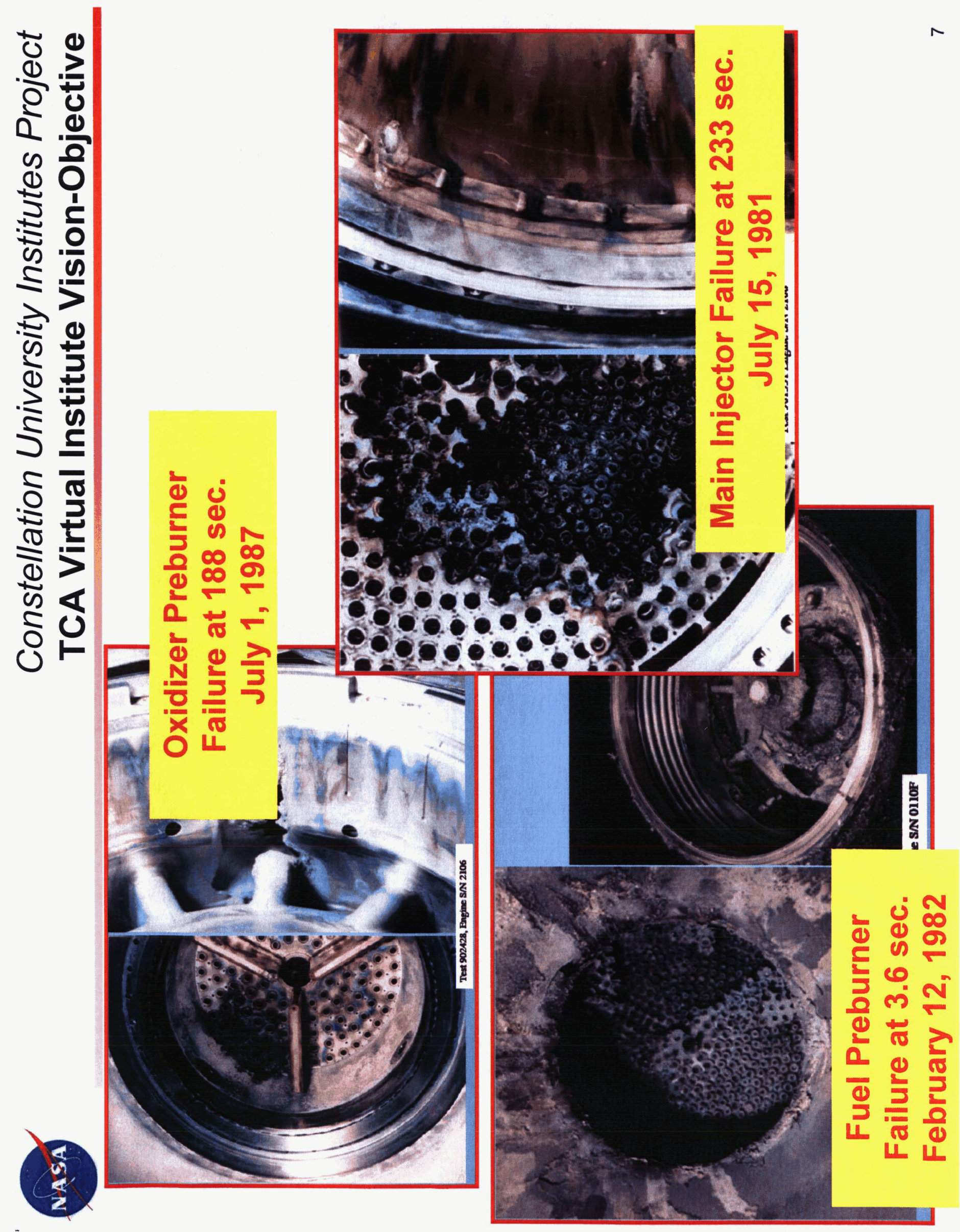




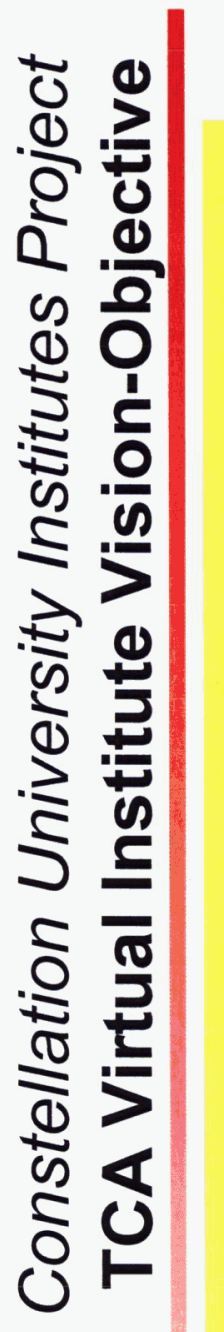

范

id

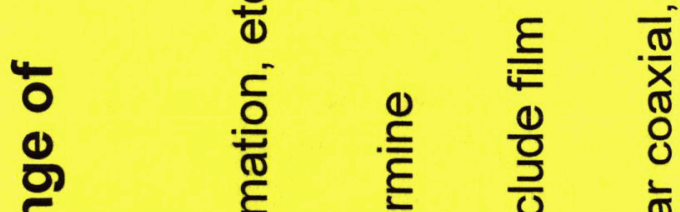

๑ क

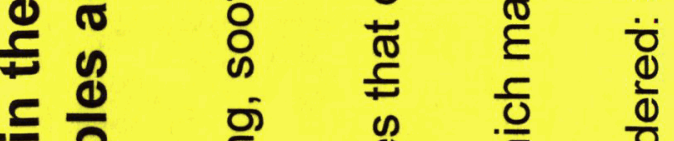

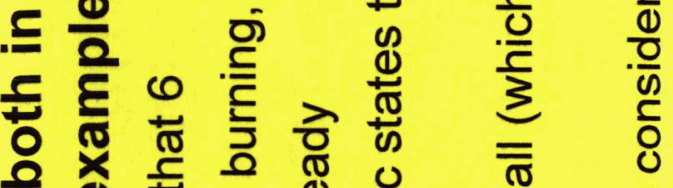

-

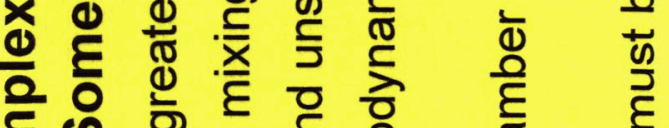

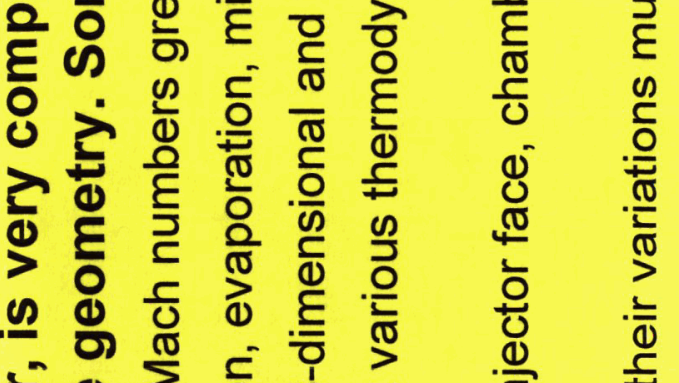

ธั่

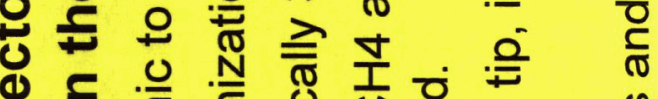

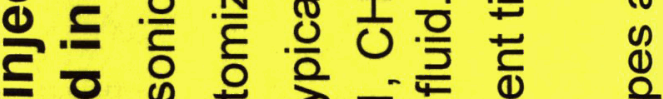

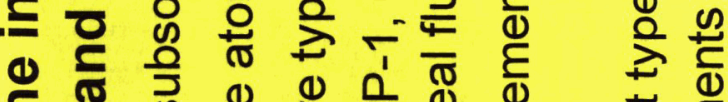

‡

๘

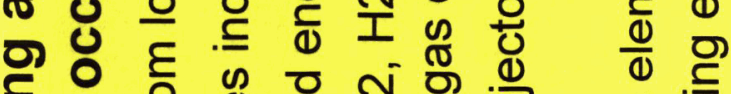

는

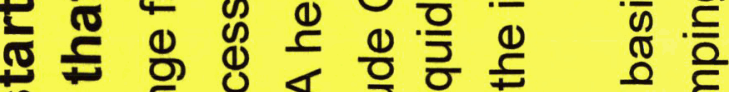

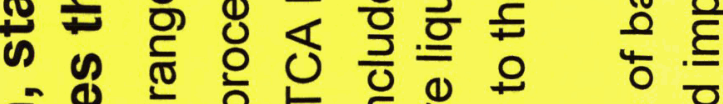

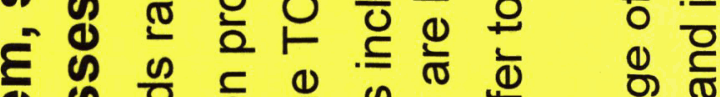

ब.

응

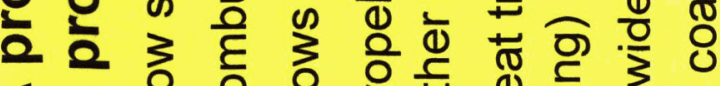

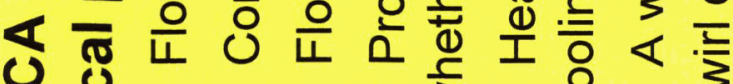

U는

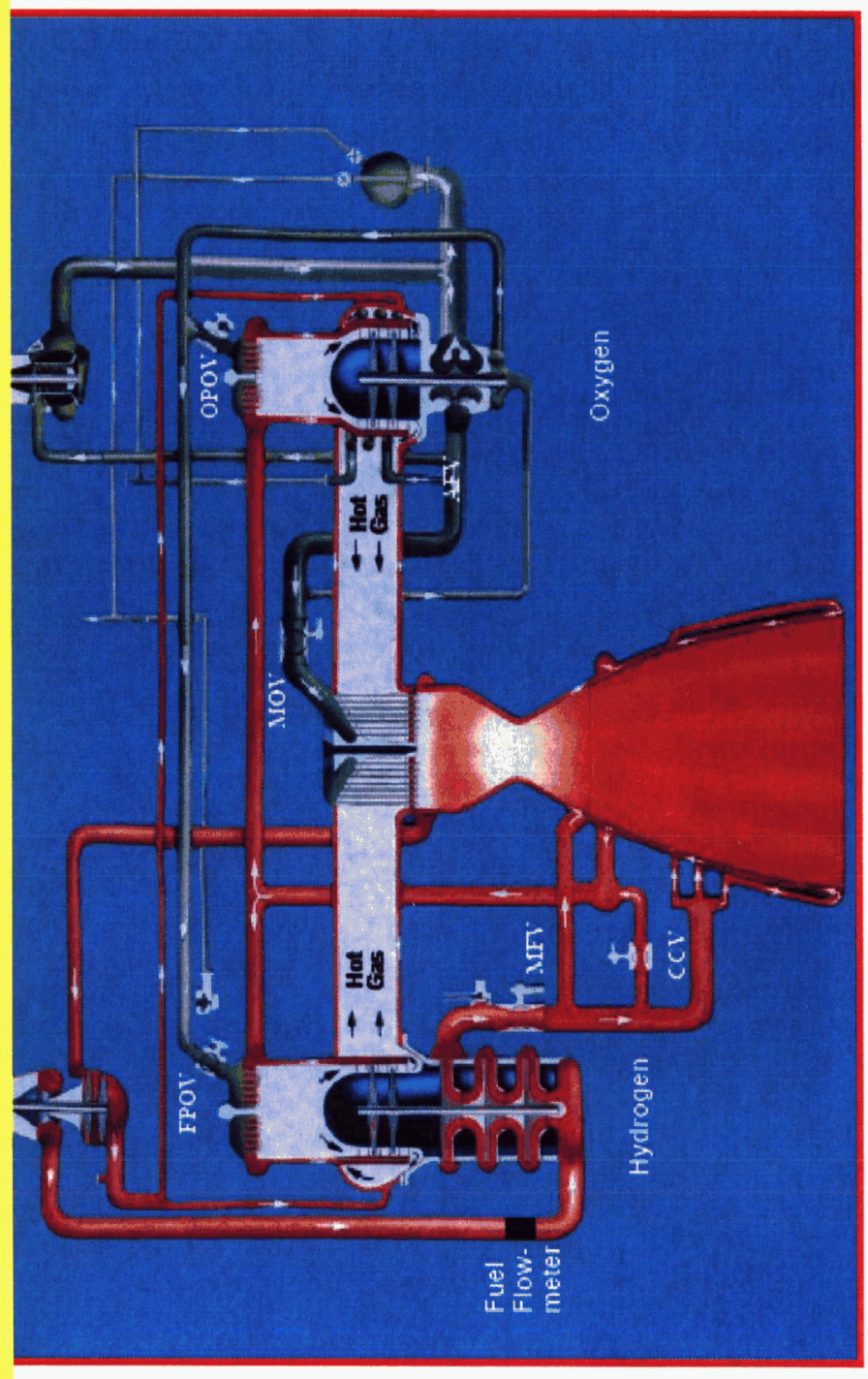

르 $\frac{1}{2}$ 

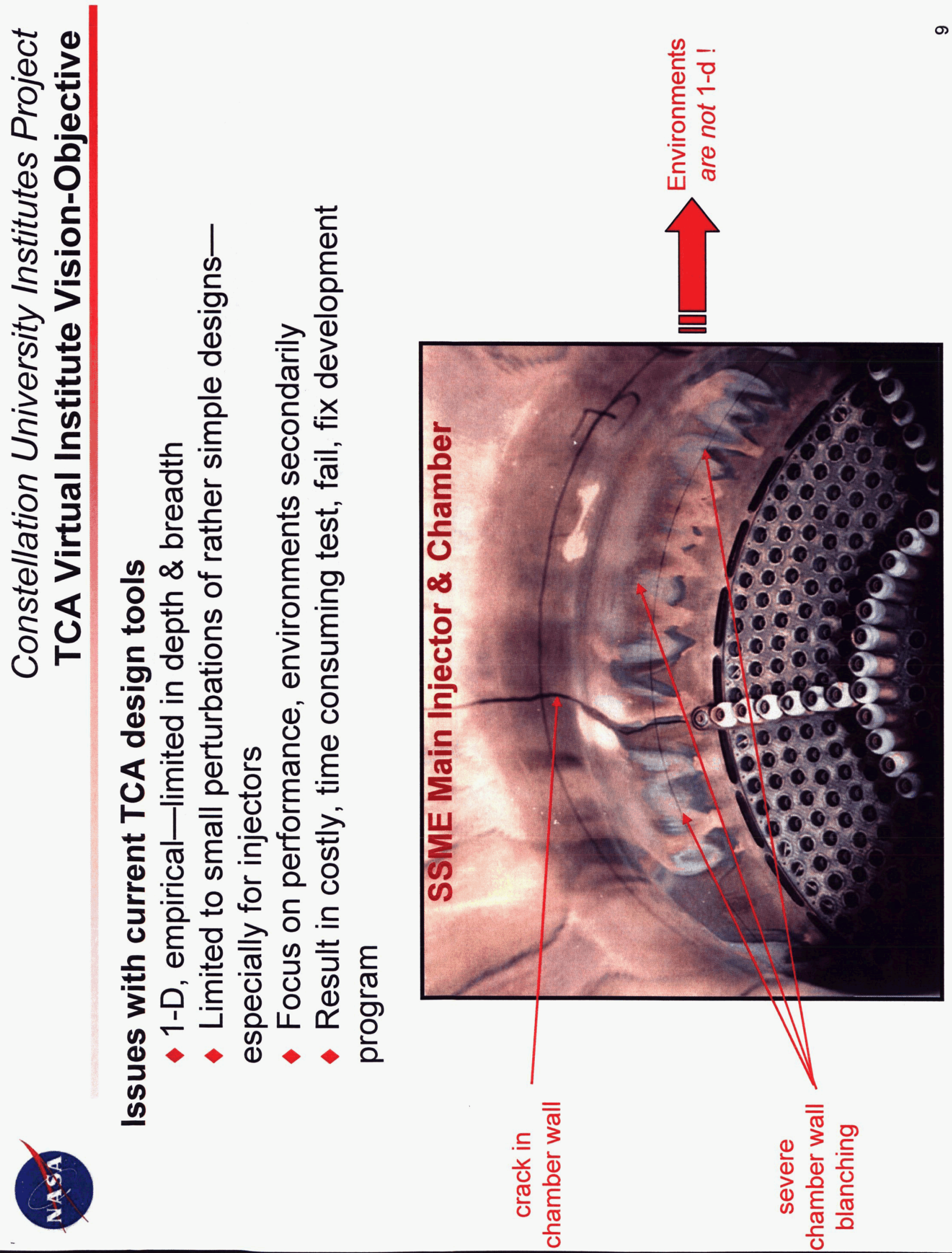

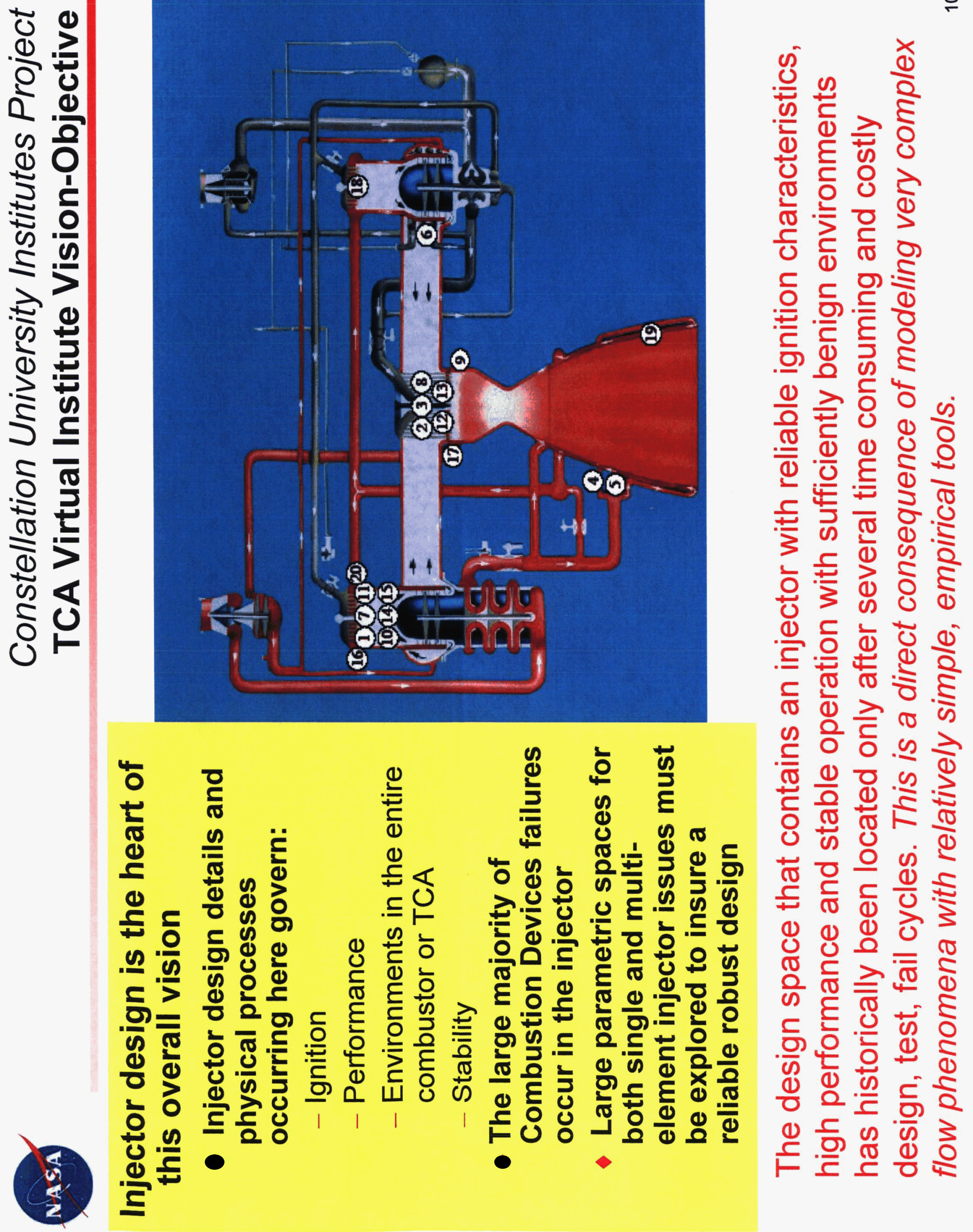
엉 त

ง $\frac{0}{0}$ 을 흘

(U)

인 궁

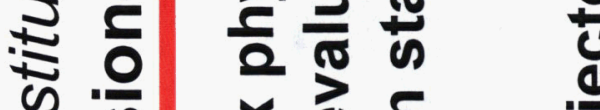

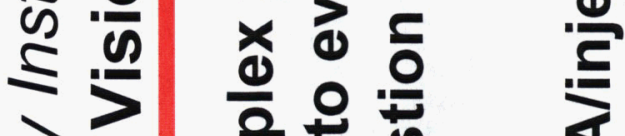

को

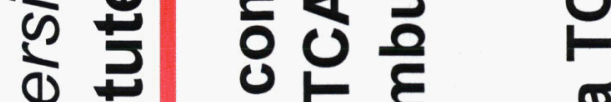

한

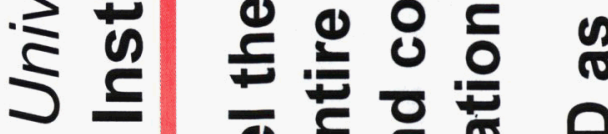

늘 융

ऽ

ब

क广

फ

Oे

¿

옹

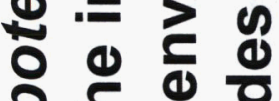

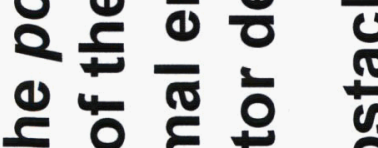

₹ $\mathrm{F}$ 웡

की \&

屯ํ.

类 ब

ธ

‡ ब

중 흥

은 늉

o is

응

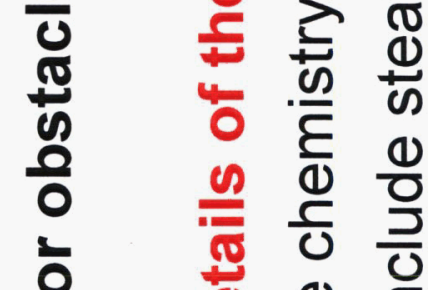

진

$\frac{1}{2}$

崩

ก

음

है है

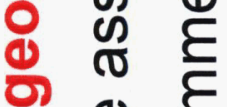

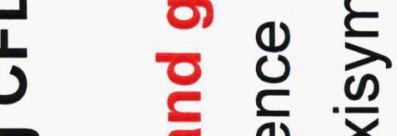

స $\frac{0}{\pi}$

웜 을

츨 흗 은

(⿻

o

요 $₫$

응 응

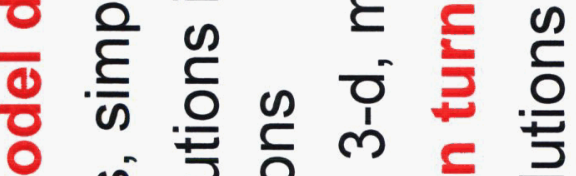

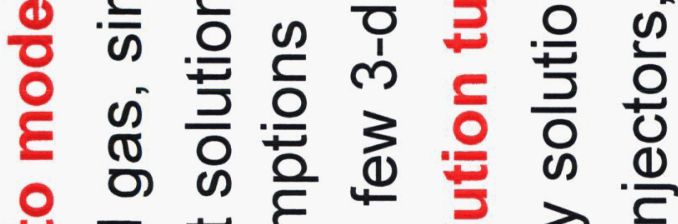

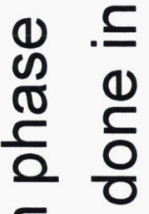

(1)

든

$\frac{1}{0} \cdot \frac{0}{2}$

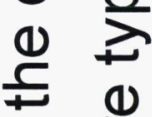

$\subseteq \frac{1}{\sigma}$

ते

(1)

व

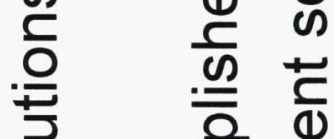

O)

$\Phi$ 更

(1)

$\frac{10}{\pi}$

용

U

(ు)

的完

$\rightarrow$ ब

to

$\frac{1}{3}$

흔 을

衣

ด 옹을

닌 응 토

흐워

क ํ. 
30

$\frac{0}{0} \geq$

व.

$\infty 2$

(1)

$\underset{1}{ }$

क 0

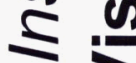

$\geqslant>$

क

(1)

$>1$

$\approx \omega$

$\nabla 2$

F 10

$+2$

단

(1)

$\infty<$

है

01
잉

잉 엄

(1) 0

(1) 응

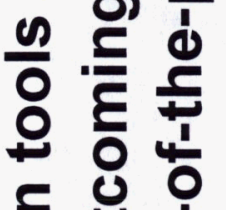

드원엉

ด 0 누

d)

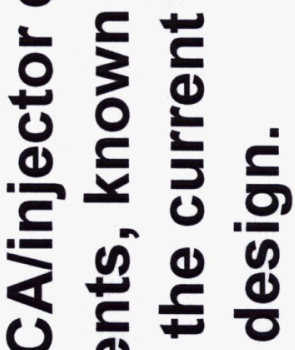

0 두

- ह 해

ฮ는

ต

잉

'은

드응

( ) 의 울

3 ด 릉

(1) 0 อ

ㄷㄴ을

은 00

군

든 이

(1)

हᄐㄷㅇㅎㅂ

울

토 는

đ 0 는

$x$ 는 $\stackrel{0}{0}$

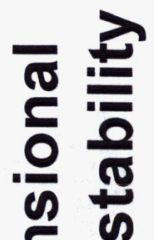

ह

d 5

토을

- क

150

를 릉

$\approx 03$

d 은

둔

를 항

릉 토은

을 든

힌의

ㅇ (1)

넌 둥

$\frac{1}{5} \frac{0}{0}$

$\frac{0}{1} \geqslant \frac{6}{0}$

을 는

운

() 올

을 들

d E 1

룬

는

인

로응

$\sum \frac{1}{2}$ 은

흘 튼

이

il 추
10

क

등 등 등

$\frac{3}{2} \frac{1}{3}$ 题

๓ $\frac{2}{0}$ 을

4 는

인 $\geq 0$

ง

ह

5

은

(1) 1

(1) क

)

들

8 (

잉

울

(1) 타

응 है

๖ 든 히 등

$+\frac{2}{2}$

क

20

E

i) $\frac{2}{10}$

로

30

๘

$>2$

울

한

है है

๘

$\rightarrow 0$

3 (1)

E

ด 3 ह

둘 흘

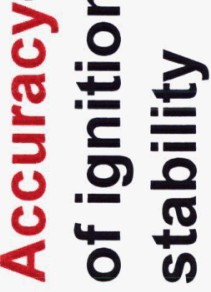




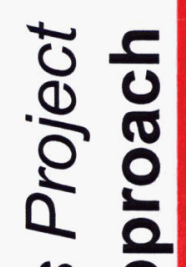

d $\frac{1}{4}$

过

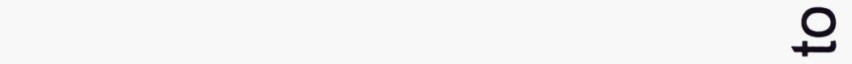

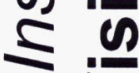

$\Rightarrow>$

$\subseteq$

$\overline{0}$

$\frac{9}{-\frac{1}{0}}$

के

?

萬

壳

$\stackrel{\oplus}{\frac{1}{2}} \stackrel{0}{\frac{1}{2}}$

ఏ

s

ร

응

.

는

岁

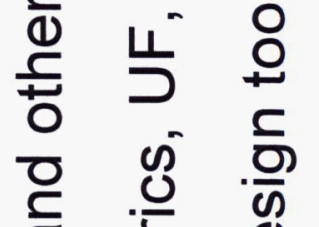

Q

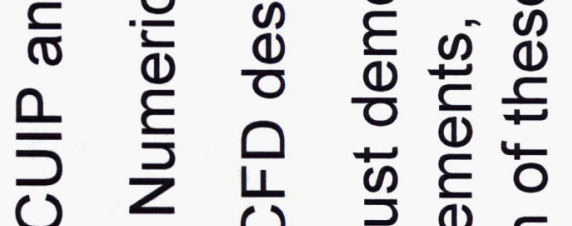

幽>

क ष

ฮ

는

空

응 음

잉

ஸे ฮ

ᄃ $ठ$

은

tक $\frac{\pi}{2}$

증

$\frac{\pi}{5}$

트 $\underline{\underline{0}}$.

ज्ञ

ब

$\sum_{\substack{0 \\ 0}}^{0}$

을 온

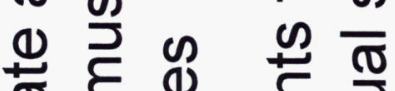

는

ᄃํํ

हो क

응드 흥

트. 그

링ํㅇ 흥

ज 응 으 흐

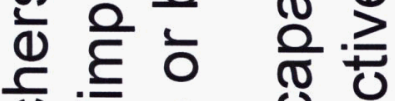

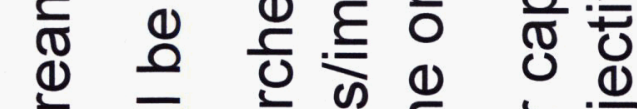

屯

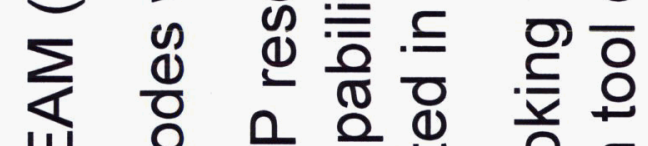

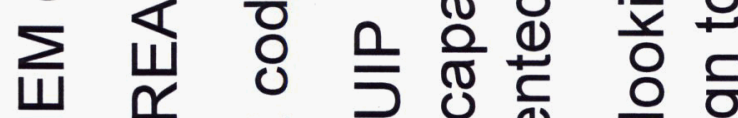

บ 호 으 믐

क E ब 


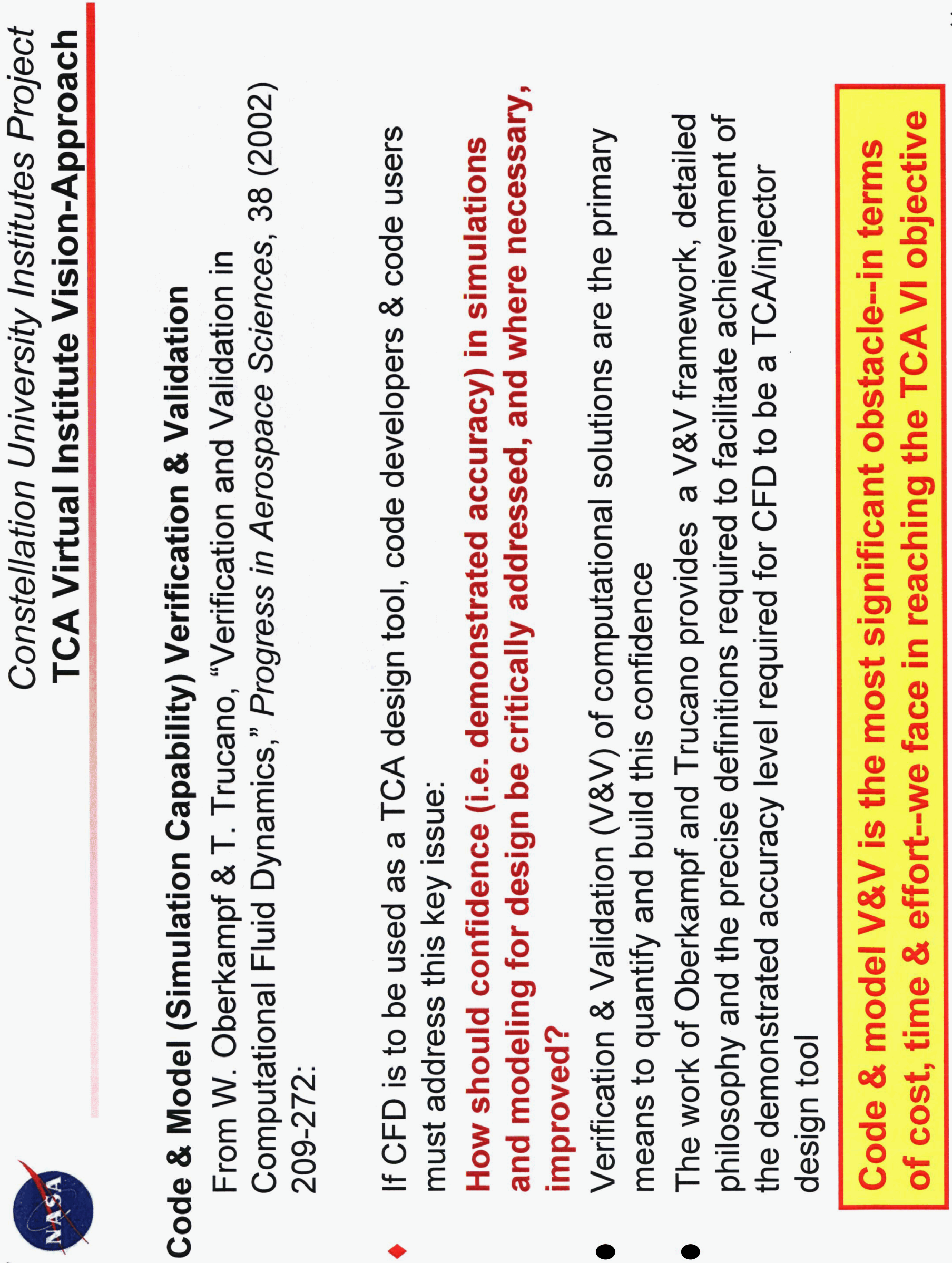




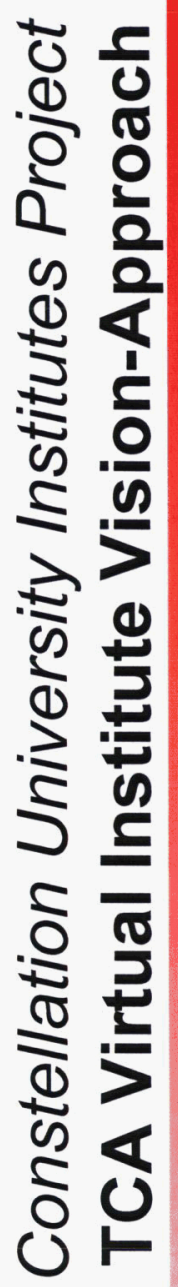

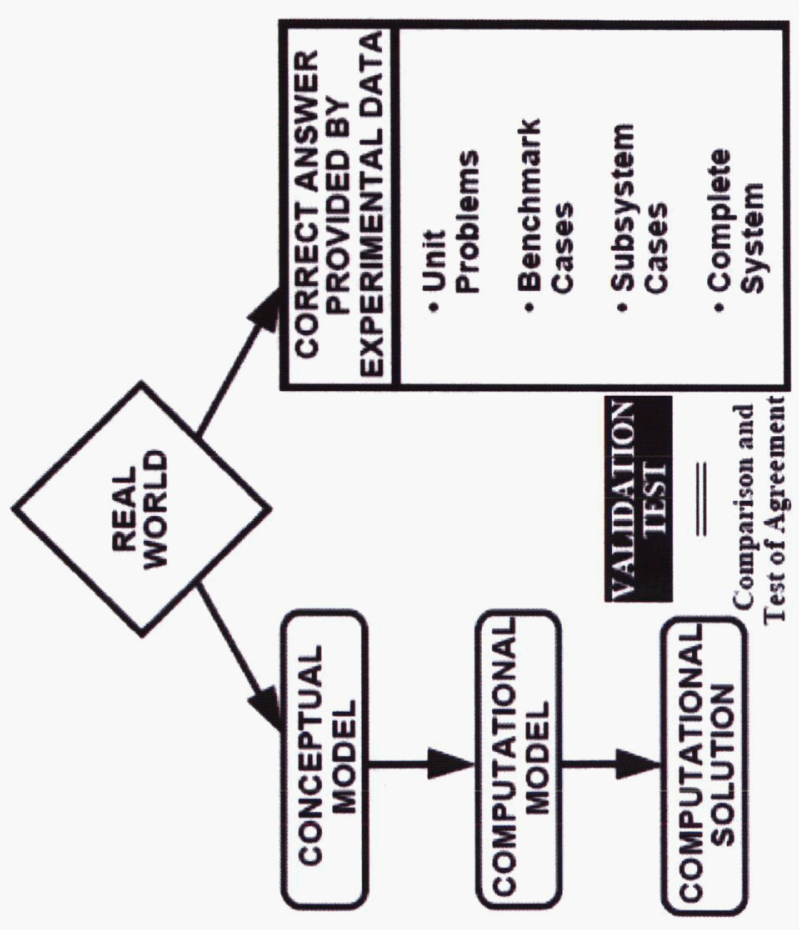

힌

$\frac{\overline{0}}{\mathrm{O}}$

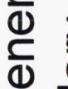

$\frac{\pi}{0}$

तั ह

을 을

हृ

है

을.

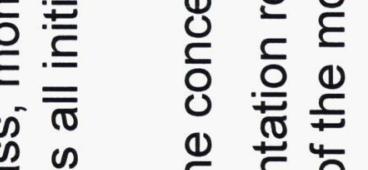

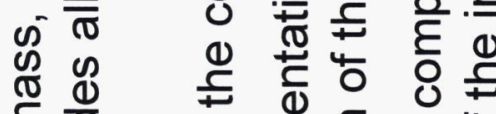

ह 을

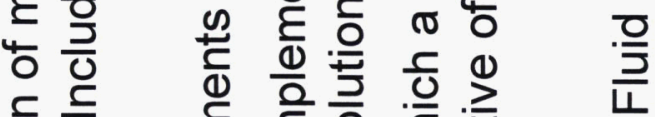

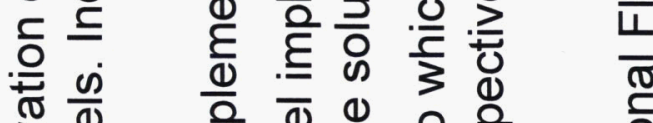

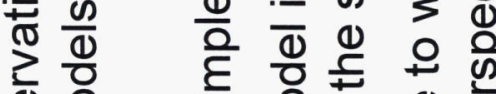

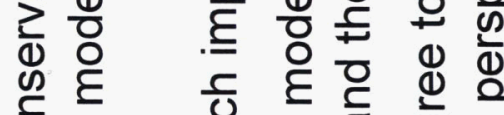

ธิ

U U

는

ญ

ํํㄴ 은

ᄋ 을 은

员

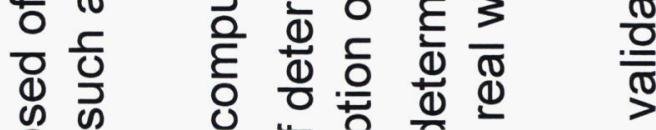

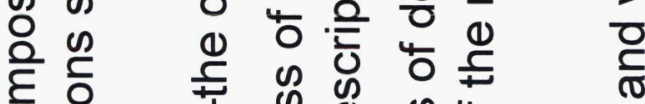

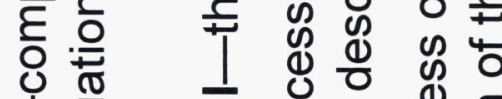

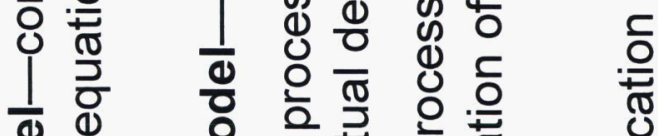

히응 을 은 음

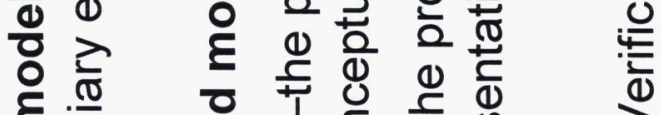

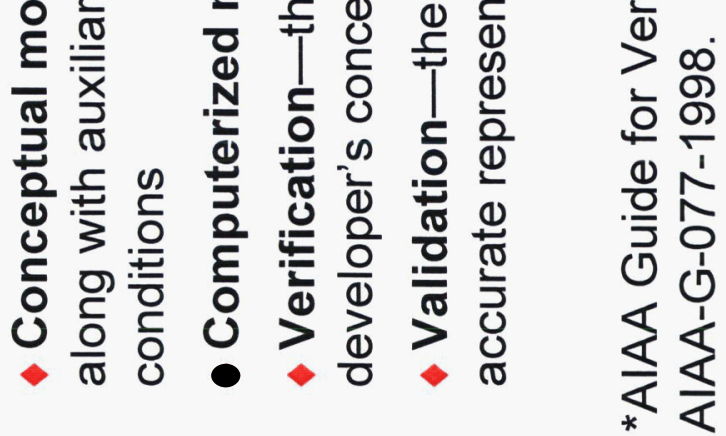




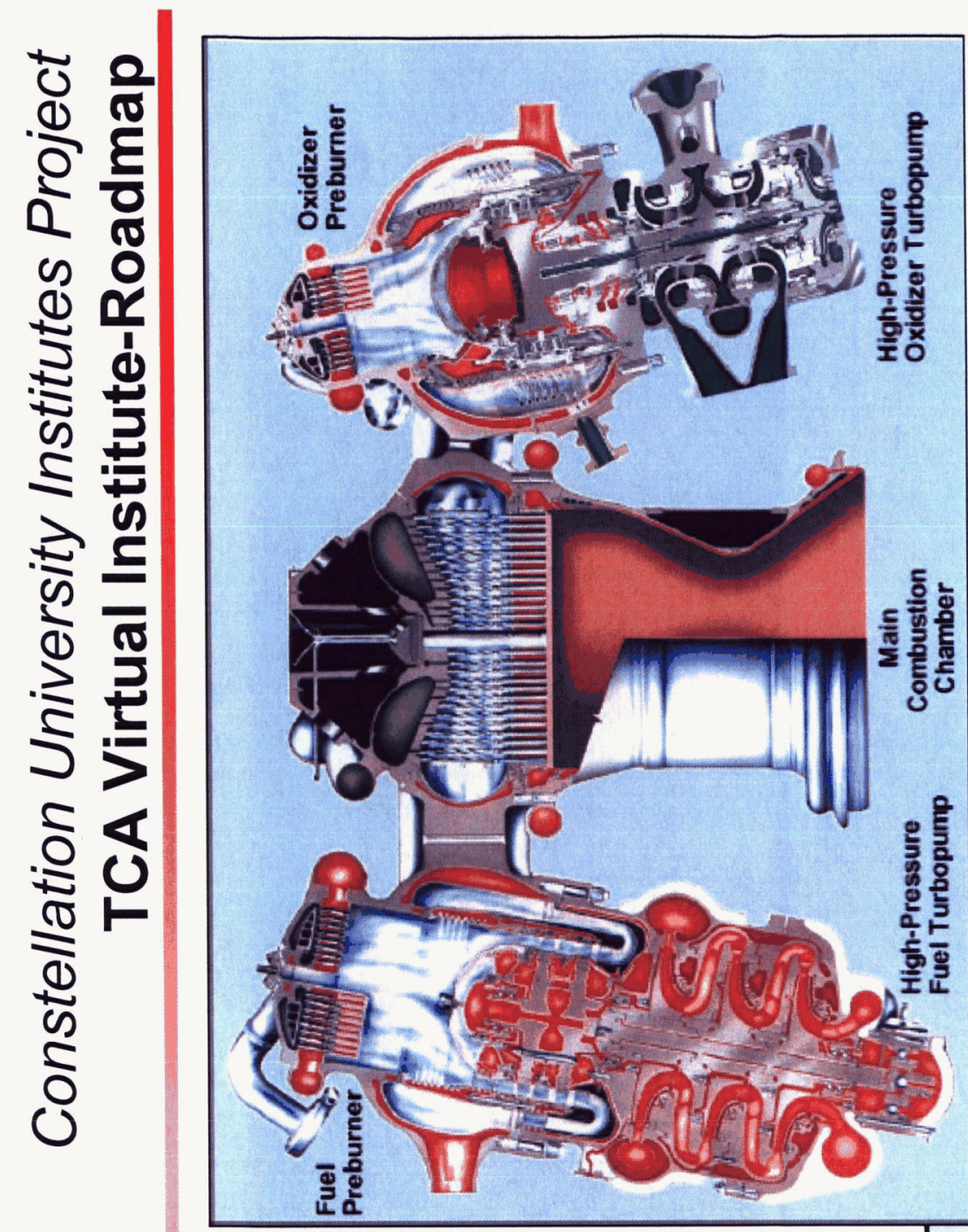

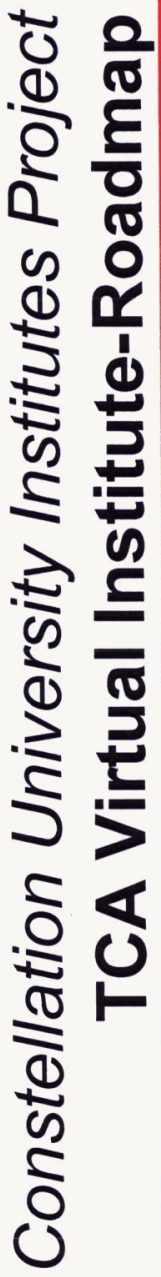

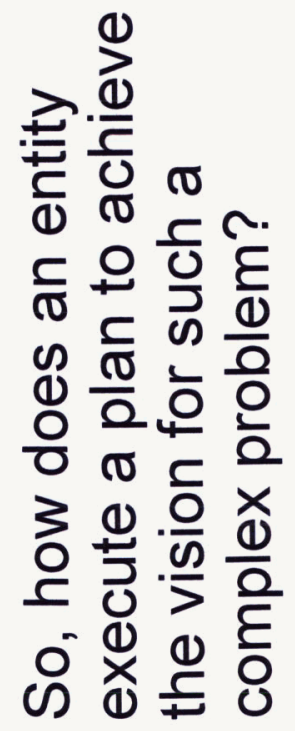

$\frac{c}{0} \quad$ is $\frac{.}{\frac{2}{0}}$

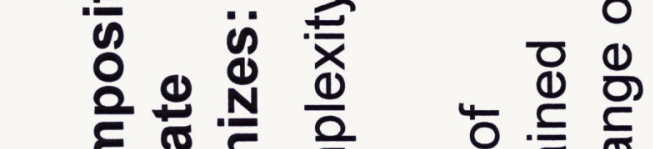

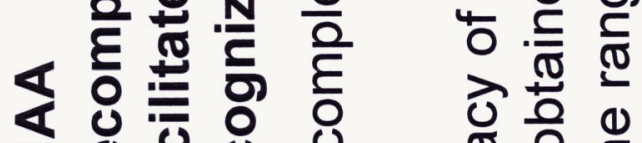

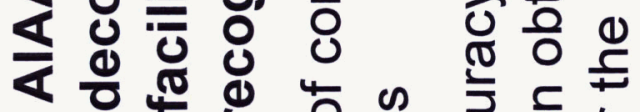

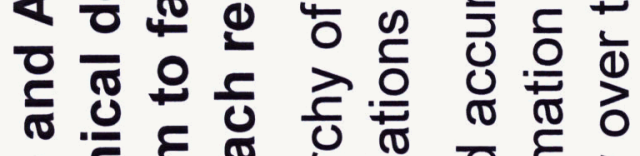

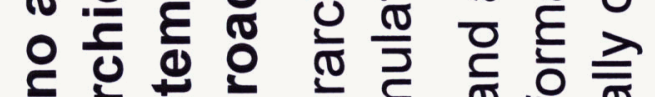

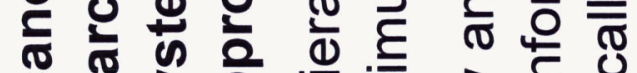

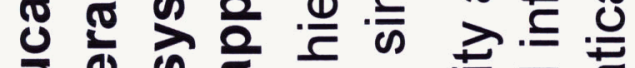

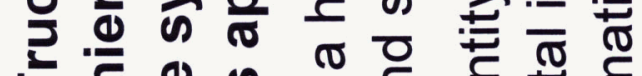

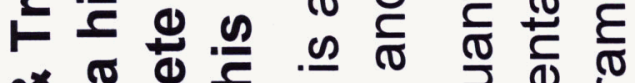

$\infty$ ర 屯

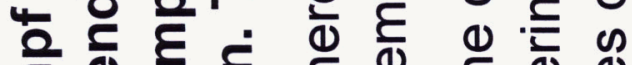

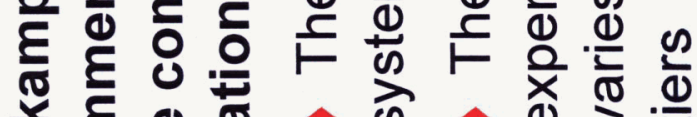

है

힝ㅇㅇ 은

○ी

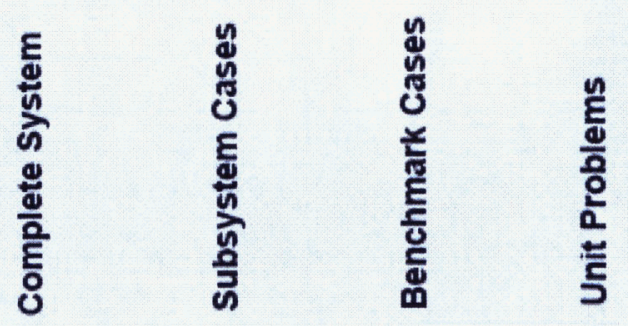

है

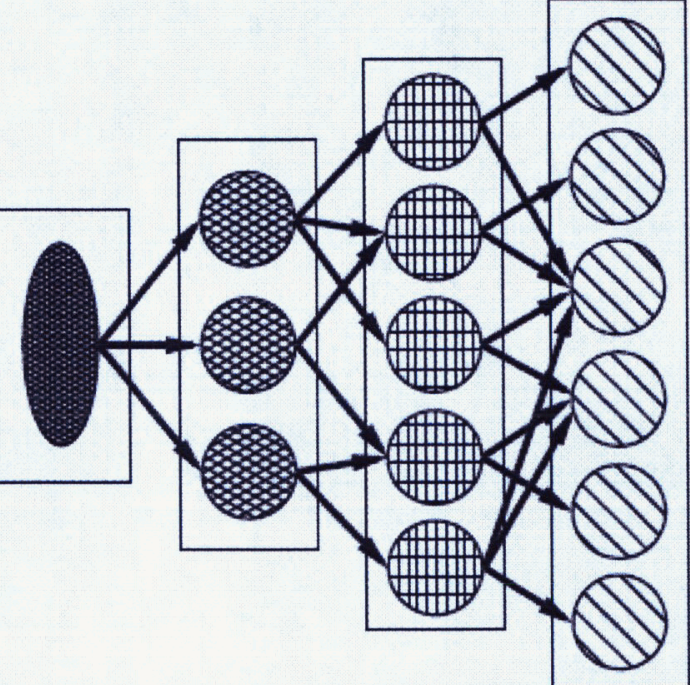




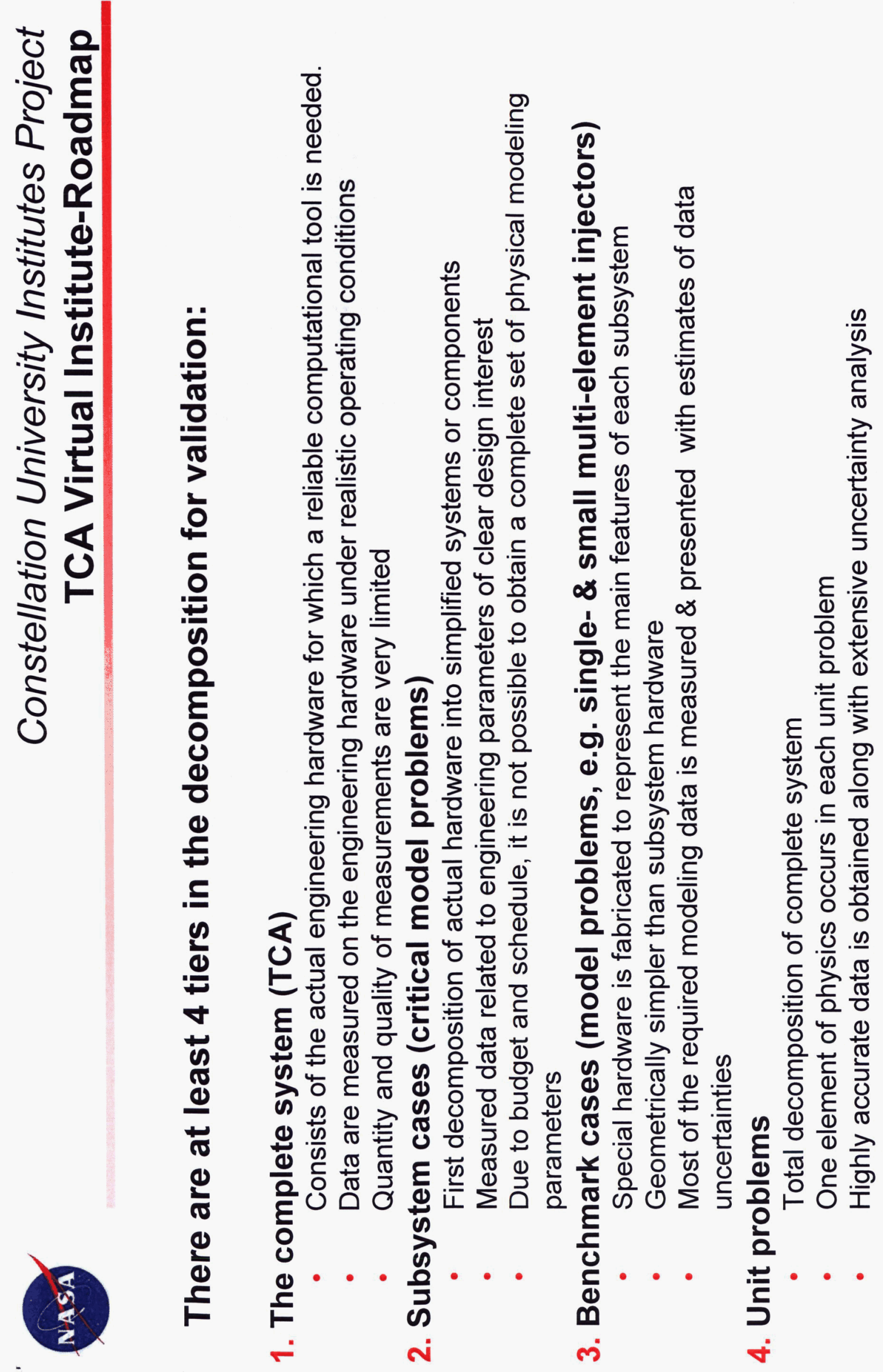




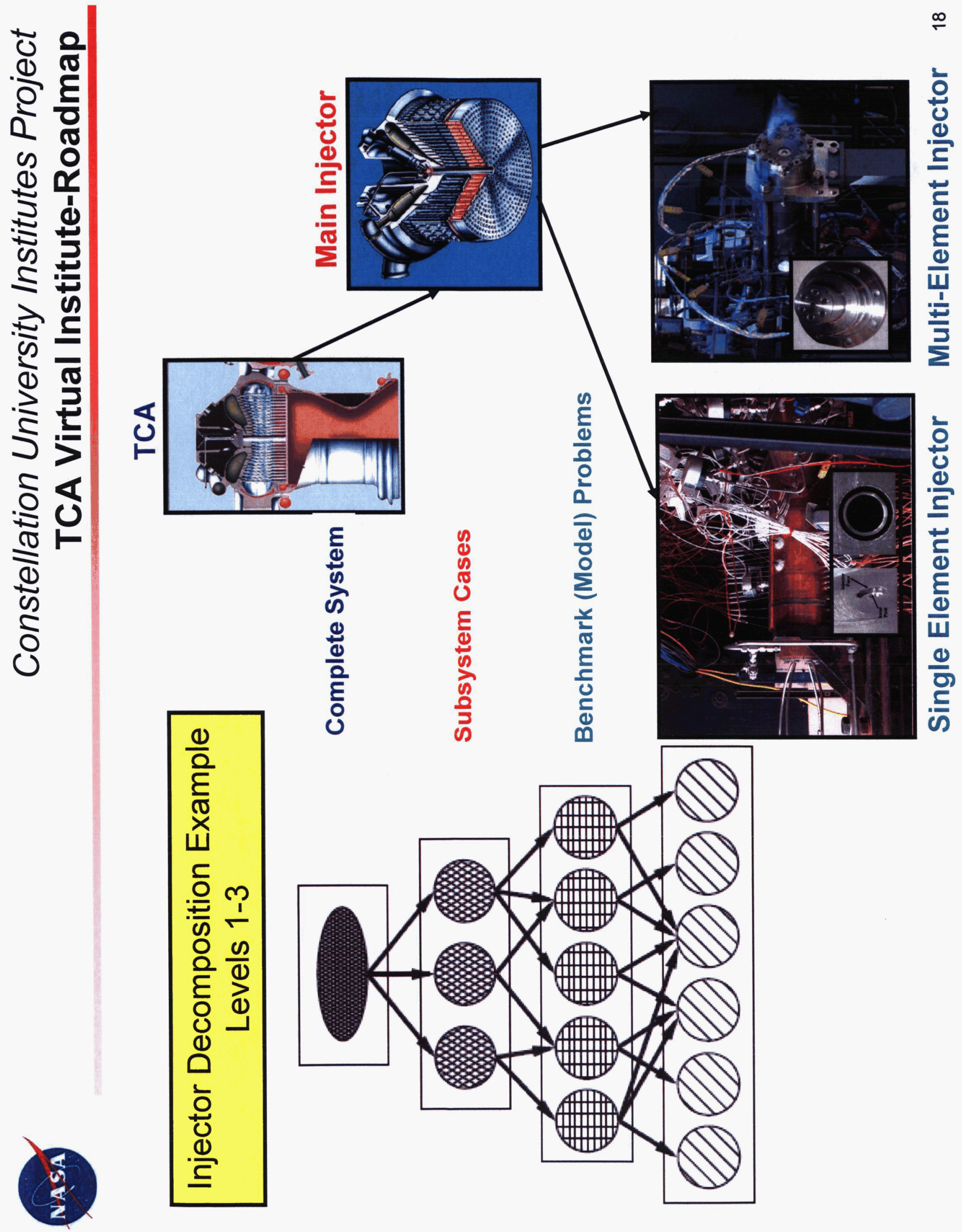



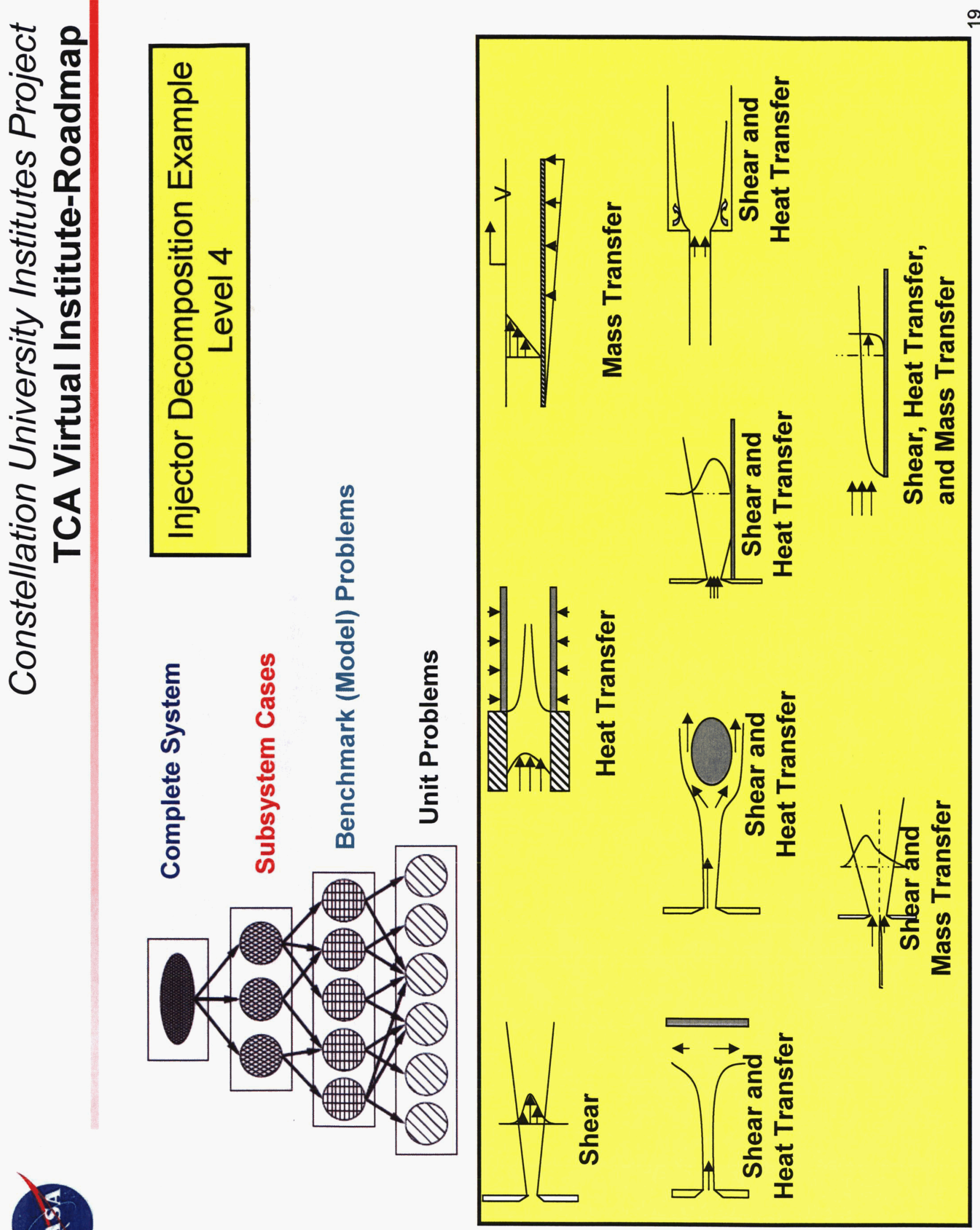

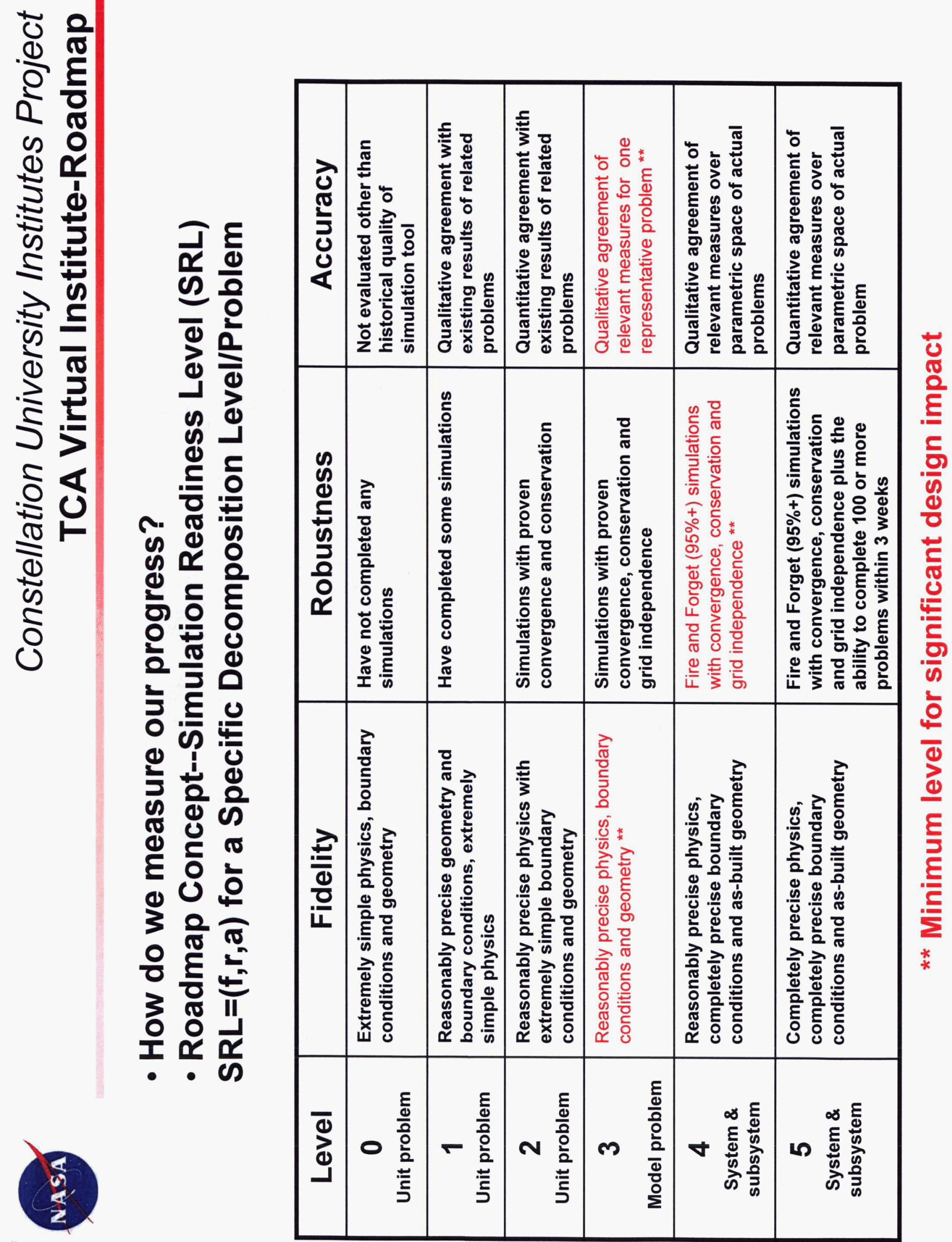


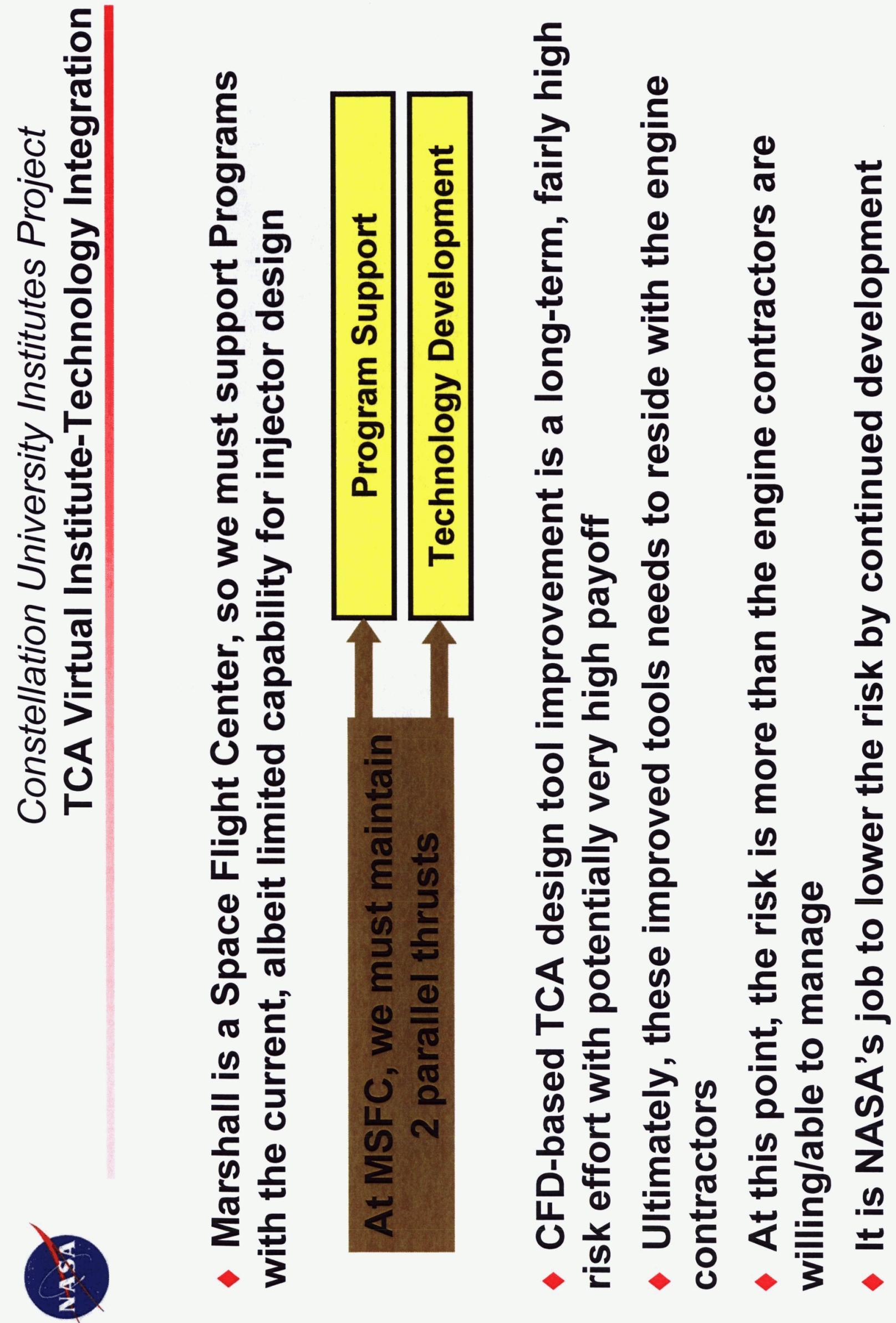



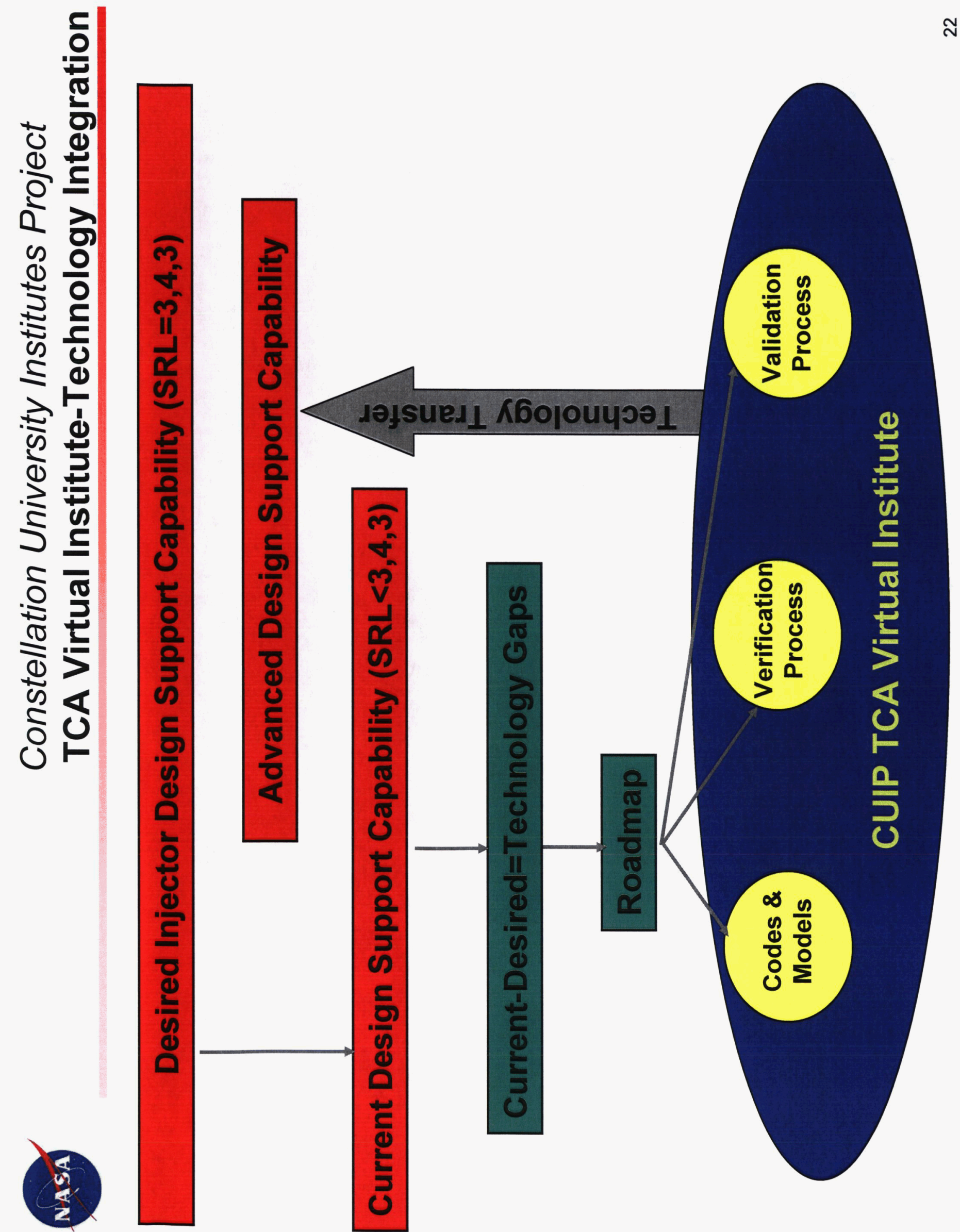
잉 $\frac{2}{4}$

(1)

a

(5) 0

$\stackrel{2}{=}$

क

$\leqslant$

$\gtrsim r$

क

(1)

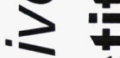

$\lesssim \mathscr{c}$

$x$

U

을

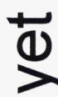

7

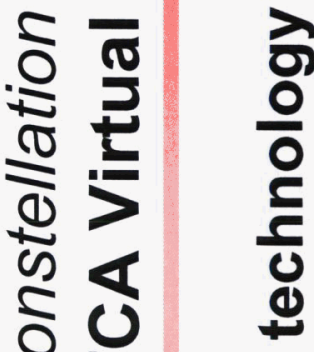

ํํㄴ

동

$\frac{0}{0}+$

흐

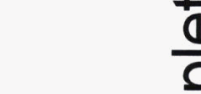

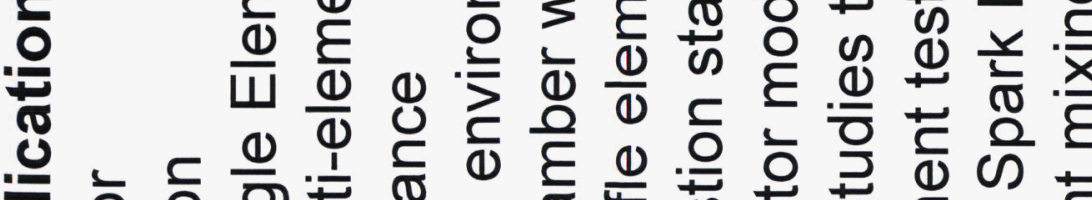

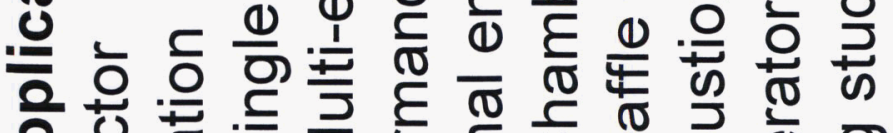

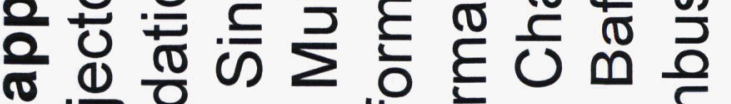
(1)

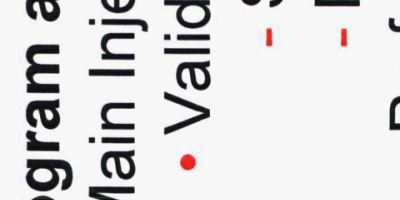
는 $\stackrel{1}{\simeq}$ ยั่

(1) С

๘

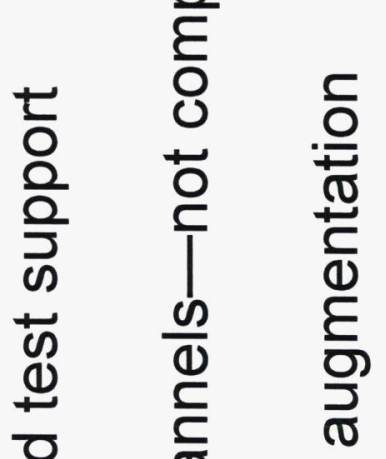

ত

ญ

ฉ 